\title{
First results from the Swarm Dedicated lonospheric Field Inversion chain
}

\author{
A. Chulliat ${ }^{1 *}$, P. Vigneron ${ }^{2}$ and G. Hulot ${ }^{2}$
}

\begin{abstract}
Data-based modeling of the magnetic field originating in the Earth's ionosphere is challenging due to the multiple timescales involved and the small spatial scales of some of the current systems, especially the equatorial electrojet (EEJ) that flows along the magnetic dip equator. The Dedicated lonospheric Field Inversion (DIFI) algorithm inverts a combination of Swarm satellite and ground observatory data at mid- to low latitudes and provides models of the solar-quiet (Sq) and EEJ magnetic fields on the ground and at satellite altitude. The basis functions of these models are spherical harmonics in quasi-dipole coordinates and Fourier series describing the 24-, 12-, 8- and 6-h periodicities, as well as the annual and semiannual variations. A 1-D conductivity model of the Earth and a 2-D conductivity model of the oceans and continents are used to separate the primary ionospheric field from its induced counterpart. First results from the DIFI algorithm confirm several well-known features of the seasonal variability and westward drift speed of the Sq current systems. They also reveal a peculiar seasonal variability of the Sq field in the Southern hemisphere and a longitudinal variability reminiscent of the EEJ wave-4 structure in the same hemisphere. These observations suggest that the Sq and EEJ currents might be electrically coupled, but only for some seasons and longitudes and more so in the Southern hemisphere than in the Northern hemisphere.
\end{abstract}

Keywords: Swarm, Geomagnetism, lonosphere, Sq, Equatorial electrojet

\section{Introduction}

Various electrical currents flow in the Earth's ionosphere. At mid- and low latitudes, thermospheric winds and tides generate electrical currents in the E-region, around 110 $\mathrm{km}$ altitude, through a process known as the ionospheric wind dynamo (Richmond and Thayer 2000). These currents take the form of two large-scale vortices on the day side of the Earth, one counterclockwise in the Northern hemisphere and the other clockwise in the Southern hemisphere. They generate magnetic fields that can be sensed on the ground, where they reach a few tens of nT, and at low Earth orbit (LEO) altitudes. These are usually referred to as Sq magnetic fields. Along the geomagnetic dip equator, a local enhancement of the electrical conductivity leads to a more intense current, the equatorial

\footnotetext{
*Correspondence: arnaud.chulliat@noaa.gov

${ }^{1}$ Cooperative Institute for Research in Environmental Sciences, University of Colorado Boulder and NOAA National Centers for Environmental Information, 325 Broadway, Boulder, CO 80305-3328, USA

Full list of author information is available at the end of the article
}

electrojet (EEJ) and magnetic fields that can reach more than $100 \mathrm{nT}$ on the ground (Forbes 1981).

Sq and EEJ magnetic fields are present on most days, even under solar and geomagnetically quiet conditions. This is unlike some higher-latitude magnetic fields, for examples fields generated by auroral electrojets that are coupled with currents in distant regions of the magnetosphere (e.g., Baumjohann and Nakamura 2009). The $\mathrm{Sq}$ and EEJ quiet-time behavior is governed by temporal variations in both the ionospheric electrical conductivity and the thermospheric winds and tides. At a fixed point at the Earth's surface, such temporal variations have a diurnal periodicity due to the rotation of the Earth. Quiet-time Sq and EEJ also vary with season (e.g., Matsushita and Maeda 1965) and solar cycle (e.g., Takeda 2002; Rastogi and Iyer 1976) and include a significant amount of day-to-day variability (e.g., Chen et al. 2007; Yamazaki et al. 2014).

Magnetic observations can be used to build empirical, climatological models of the Sq and EEJ fields. Earlier models (see, e.g., the review by Campbell 1989) were 
derived from ground data only and generally described the Sq field as a latitude and local time-dependent equivalent current system. This approach, when applied to a dense meridional chain of stations, provides a detailed description of the Sq field and its climatology in a given longitudinal sector (Yamazaki et al. 2011). However, the global observatory network, even complemented by additional variometer networks, is too sparse to provide adequate coverage at all latitudes and longitudes, especially in the equatorial area. Another approach, pioneered by Sabaka et al. (2002) in their Comprehensive Model (CM), consists in building a time-dependent, spherical harmonic model of the Sq and EEJ fields from a combination of observatory and satellite magnetic measurements. The resulting model provides the Sq and EEJ fields at every location at the Earth's surface and at satellite altitude, assuming that ionospheric currents are confined to an horizontal layer at $110 \mathrm{~km}$ altitude. Diurnal and seasonal variations are described by Fourier series, and a mantle conductivity model is used to calculate the effect of induction on each spatial and temporal harmonic. Subsequent versions of the $\mathrm{CM}$ relied on an increasing number of satellite data collected over the past decade (Sabaka et al. 2004, 2015).

The European Space Agency (ESA) Swarm satellite mission, launched in November 2013, has been providing high-quality magnetic data collected onboard three identical satellites, including two in different local times. As part of the Swarm level 2 project (Olsen et al. 2013), we developed the Dedicated Ionospheric Field Inversion (DIFI) algorithm to calculate empirical, climatological models of the Sq and EEJ fields from Swarm data. The DIFI algorithm uses a parameterization very close to that of the CM, but unlike this model inverts for the ionospheric field only after having removed all other field contributions from the data. An earlier version of DIFI was fully tested with synthetic data prior to the launch of mission (Chulliat et al. 2013). Since then, several improvements were made to the algorithm, pertaining to how data are preprocessed, model regularization and the use of observatory data. In the present paper, we report on the first results from the DIFI algorithm applied to Swarm data.

\section{Model calculation}

\section{Data}

The DIFI models described in this paper were derived from a combination of Swarm satellite data and ground observatory data. The Swarm data were acquired between December 1, 2013, and July 17, 2015. The observatory data cover the time interval December 1, 2013, to February 22, 2015.
The Swarm mission consists of three identical satellites in low Earth, near-polar orbits simultaneously launched on November 23, 2013, at an initial altitude of slightly more than $500 \mathrm{~km}$ (with respect to a reference radius of $6371.2 \mathrm{~km}$ ). Subsequent maneuvers between end of January and mid-April 2014 brought Swarm A and C to sideby-side orbits of inclination $87.4^{\circ}$, separated by roughly $150 \mathrm{~km}$ at the equator, and at an altitude decaying from $475 \mathrm{~km}$ in mid-April 2014 to slightly less than $460 \mathrm{~km}$ in mid-July 2015. Similar maneuvers between mid-February and mid-March 2014 brought Swarm B on a slightly different inclination of $88^{\circ}$ and at an altitude of a little less than $525 \mathrm{~km}$ which since slowly decayed to slightly more than $515 \mathrm{~km}$ in mid-July 2015. All three satellites are equipped with the same scientific instruments, including: a fluxgate, vector field magnetometer (VFM, and a spare) providing vector measurements of the ambient magnetic field; a set of three star trackers providing accurate attitude measurements; an helium-4, absolute scalar magnetometer (ASM, and a spare), providing measurements of the modulus of the ambient magnetic field at an accuracy better than $0.3 \mathrm{nT}$ (see, e.g., Olsen et al. 2015), as well as vector measurements as part of the successful ASM-V experiment (see Hulot et al. 2015; Léger et al. 2015; Vigneron et al. 2015).

Achieving a good local time coverage is critical to ionospheric field modeling, if one wants to disentangle longitude, local time and seasonal dependence of the Sq and EEJ fields. The Swarm constellation was designed to address this goal (see Friis-Christensen et al. 2006). The satellites drift in local time at a rate of about $2.7 \mathrm{~h}$ per month, so that each satellite surveys the same local time approximately every 4.4 months (Fig. 1). In addition, and thanks to its different orbit, B now drifts slightly faster than $A$ and $C$. As a result, the local time separation between $A$ (and $C$ ) and B increased over time, from close to zero just after the launch to about 2 hrs in July 2015. The maximum possible separation of 6 hrs (for two satellites or groups of satellites) is expected to be reached in mid-2017, a few months before the end of Swarm's current nominal lifetime.

In the present modeling study, we used level $1 \mathrm{~b}$ vector data, baseline 0405, retrieved from the European Space Agency Web site. We only used data from the A and B satellites. Data from the $C$ satellite were not used for two reasons. First, the local time separation between $\mathrm{A}$ and $\mathrm{C}$ is very small compared with the longitudinal spatial scales of the Sq and EEJ fields, and therefore the two satellites are redundant when modeling these fields. Second, vector data provided by the A satellite are expected to be of better quality because ASM instruments onboard C ceased to deliver data on November 5, 2014 (Fratter et al. 

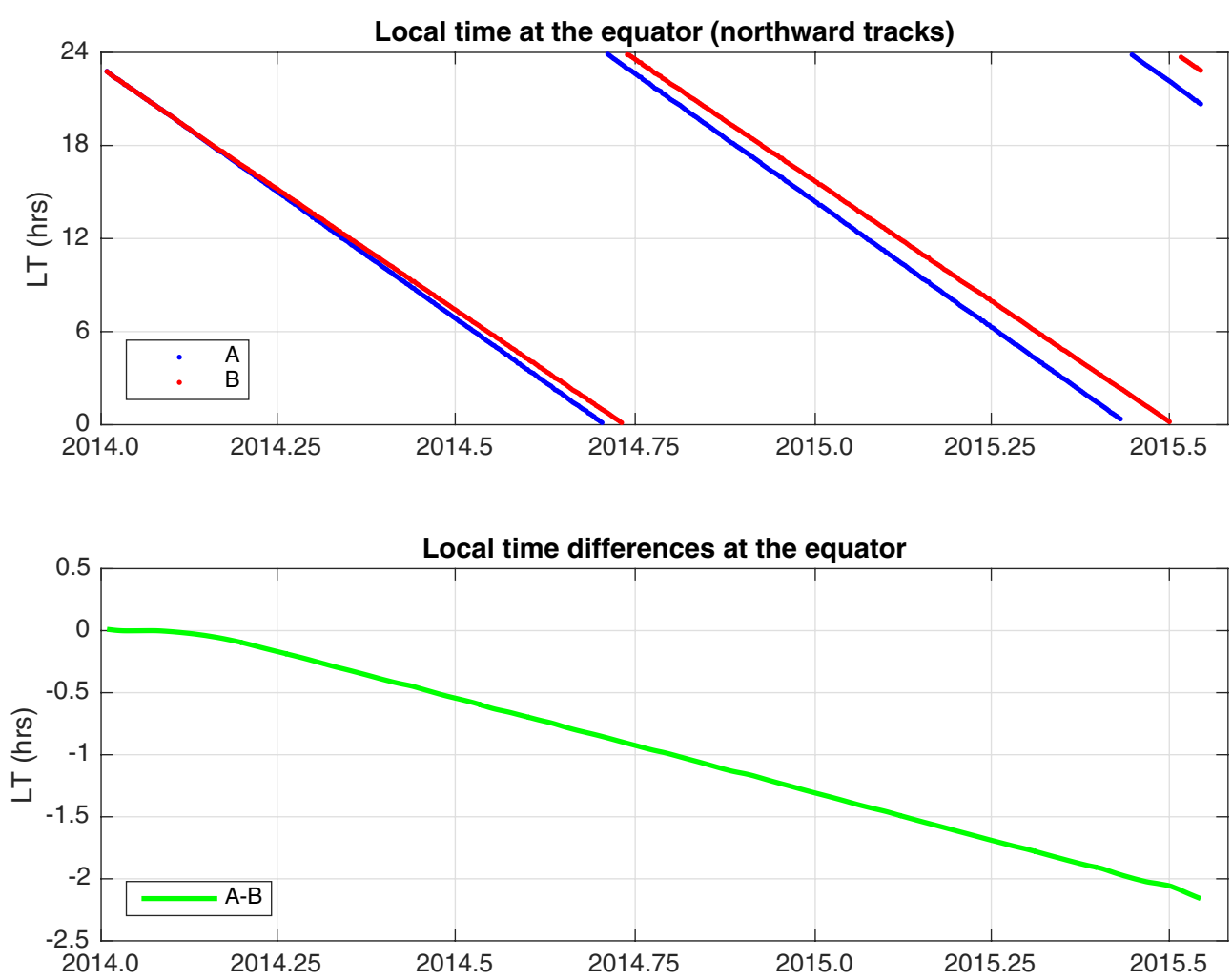

Fig. 1 (Top) Local time drift of the Swarm A and B satellites between January 1, 2014, and July 31, 2015. (Bottom) Evolution in time of the local time separation between $A$ and $B$ over the same time interval

2016), and the VFM instrument onboard C had to be calibrated using ASM scalar data from the A satellite.

Observatory hourly mean values were retrieved from the Swarm level 2 project server for the following 79 observatories: API, ASC, ASP, BDV, BEL, BGY, BOU, BOX, CDP, CKI, CLF, CNB, CTA, CZT, DLT, DOU, EBR, ELT, ESA, EYR, FRD, FRN, FUR, GAN, GLM, GNG, GUA, HAD, HER, HON, HRB, HUA, HYB, IPM, IRT, IZN, KAK, KDU, KEP, KHB, KNY, KNZ, KOU, KSH, LIV, LRM, LZH, MAB, MBO, MIZ, MMB, MZL, NEW, NGK, NVS, ORC, PAG, PET, PHU, PST, QGZ, QIX, QZH, SBL, SFS, SHU, SJG, SPT, SUA, TAM, TDC, THJ, THY, TRW, TUC, VIC, WHN, WNG, YAK (Fig. 2, full name and location of each observatory available at http://www.bgs. ac.uk/iaga/vobs/home.html). These data were compiled by the British Geological Survey (Macmillan and Olsen 2013) and include definitive and quasi-definitive data. Definitive data are data that have been baseline-corrected and thoroughly checked; they are usually released a few months after the end of each civil year. Quasi-definitive data are baseline-corrected data released shortly after their acquisition (Peltier and Chulliat 2010). Although the baseline is later discarded in the processing of observatory data, relying on quasi-definitive or definitive data ensures that the data have undergone at least minimal quality control.

\section{Data preprocessing}

The general satellite data preprocessing workflow is described in Chulliat et al. (2013). The first step, data selection, aims at extracting quiet-time data from the initial dataset. We used the following selection criteria for that purpose: $K_{p}<2 \mathrm{o},\left|D_{s t}\right|<20 \mathrm{nT},-8<\operatorname{IMF} B y<8$ and $-2<$ IMF $B z<6$ (where IMF stands for interplanetary magnetic field). All indices were also retrieved from the Swarm level 2 server. The data were subsequently decimated to one sample every $60 \mathrm{~s}$.

Working with real data instead of synthetic data led us to make several modifications to the way data were corrected prior to the inversion. Data corrections were applied for the core, crustal and magnetospheric fields using the following models: (a) a Swarm-based, core field model derived by Patrick Alken (University of Colorado Boulder) using an algorithm recently developed for the IGRF project (Alken et al. 2015a), (b) the MF7 lithospheric field model, which can be retrieved from https://geomag.colorado.edu/magnetic-field-model-mf7. html and uses more recent CHAMP data but a similar 


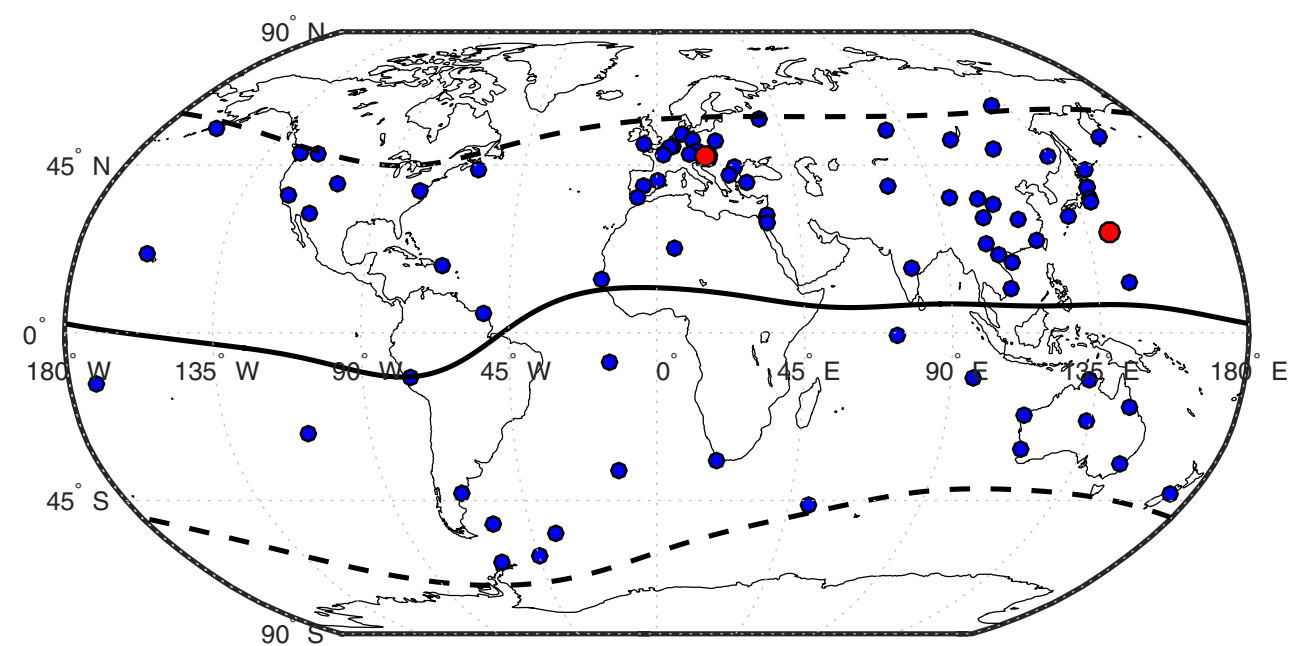

Fig. 2 Map of magnetic observatories, the data of which were used as inputs of the DIFI algorithm (blue dots) or as independent data when validating the DIFI model (red dots). Quasi-dipole latitudes $\pm 55^{\circ}$ are shown as dashed black lines. The magnetic dip equator is depicted as a thick black line

methodology as the earlier MF6 model (Maus et al. 2008); (c) the POMME-6 magnetospheric field model (Maus and Lühr 2005; Lühr and Maus 2010). In addition to these model-based corrections, empirical track-by-track corrections were applied in order to remove the remaining magnetospheric field. For each nightside track between 2100 and 0300 local time (LT), a degree one external field in dipole coordinates and its induced counterpart (using a ratio of 0.27 ) were fitted to the data between dipole latitudes $\pm 40^{\circ}$. The obtained degree one models were then interpolated on the dayside, assuming the magnetospheric field would not vary substantially over the time (less than $1 \mathrm{~h}$ ) the satellite takes to go from nightside to dayside. The final set of models was used to correct all data.

Once corrected, high-latitude satellite data were downweighted using a low-pass filter with respect to dipole latitude. We used a Tukey (tapered cosine) window defined as:
Observatory data were selected using the same criteria as for the satellite data and were not further decimated. They were corrected using the Swarm level 2 models for the core (Rother et al. 2013), crustal (Thébault et al. 2013) and magnetospheric (Hamilton 2013) fields. The average night time level was then determined for each day using values between 2100 and $0300 \mathrm{LT}$ and subsequently removed from the data.

The preprocessing yielded 404,068 satellite data point triples and 242,485 observatory data point triples, covering the time interval December 1, 2013, to July 17, 2015.

\section{Model parameterization}

The model parameterization was presented in depth in Chulliat et al. (2013). Here we summarize the most important aspects for the purpose of presenting and discussing the modeling results in "Results" section and specify the parameters and auxiliary data used.

$$
w\left(\theta_{q d}\right)= \begin{cases}\frac{1}{2}\left\{1+\cos \left[\pi\left(\frac{\theta_{q d}}{\theta_{0}}-1\right)\right]\right\} & \text { for } \theta_{q d}<\theta_{0} \\ 1 & \text { for } \theta_{0} \leq \theta_{q d} \leq 180-\theta_{0} \\ \frac{1}{2}\left\{1+\cos \left[\pi\left(\frac{\theta_{q d}}{\theta_{0}}-\frac{180}{\theta_{0}}+1\right)\right]\right\} & \text { for } \theta_{q d}>180-\theta_{0}\end{cases}
$$

where $\theta_{q d}$ is the quasi-dipole (QD) colatitude (Richmond 1995), $\theta_{0}=45^{\circ}$ between 0600 and $1800 \mathrm{LT}$ and $\theta_{0}=50^{\circ}$ before 0600 and after 1800 LT. This procedure effectively damps the residual signal at high latitudes, i.e., outside areas where $\mathrm{Sq}$ and EEJ currents develop, while minimizing the Gibbs effect in the final model. It follows that the domain of validity of the model is the area between quasi-dipole latitudes $\pm 55^{\circ}$.
Assuming that the Sq and EEJ currents flow at an altitude of $h=110 \mathrm{~km}$, the DIFI models describe spatial, diurnal, seasonal and solar cycle variations of the primary and secondary (induced) Sq and EEJ fields between the Earth's surface and the altitude $h$, and above that altitude. The total ionospheric field $\boldsymbol{B}$ in these regions (i.e., outside sources) may be expressed as a potential field: $\boldsymbol{B}=-\nabla\left(V_{1}+V_{2}\right)$, where $V_{1}$ and $V_{2}$ are magnetic 
potentials for the primary and secondary fields, respectively. We used the following general forms for the primary field potential, $V_{1}$, below and above the current layer, respectively:

$$
\begin{aligned}
V_{1}\left(r, \theta_{d}, \phi_{d}, t, t_{m}\right) \\
=\left(1+N \times F_{10.7}\right) \\
\quad \sum_{s=s_{\min }}^{s_{\max }} \sum_{p=p_{\min }}^{p_{\max }} \sum_{n=1}^{N_{\max }} \sum_{m=0}^{M_{\max }} a\left(\frac{r}{a}\right)^{n} P_{n}^{m}\left(\theta_{d}\right) \\
\quad\left\{\left[q_{n s p}^{m(c)} \cos m \phi_{d}+s_{n s p}^{m(c)} \sin m \phi_{d}\right] \cos \left(\omega_{s} s t+\omega_{p} p t_{m}\right)\right. \\
\left.\quad+\left[q_{n s p}^{m(s)} \cos m \phi_{d}+s_{n s p}^{m(s)} \sin m \phi_{d}\right] \sin \left(\omega_{s} s t+\omega_{p} p t_{m}\right)\right\}
\end{aligned}
$$$$
\text { for } a<r<a+h
$$

$$
\begin{aligned}
& V_{1}\left(r, \theta_{d}, \phi_{d}, t, t_{m}\right) \\
& =\left(1+N \times F_{10.7}\right) \\
& \quad \sum_{s=s_{\min }}^{s_{\max }} \sum_{p=p_{\min }}^{p_{\max }} \sum_{n=1}^{N_{\max }} \sum_{m=0}^{M_{\max }} a\left(\frac{a}{r}\right)^{n+1} P_{n}^{m}\left(\theta_{d}\right) \\
& \quad\left\{\left[g_{n s p}^{m(c)} \cos m \phi_{d}+h_{n s p}^{m(c)} \sin m \phi_{d}\right] \cos \left(\omega_{s} s t+\omega_{p} p t_{m}\right)\right. \\
& \left.\quad+\left[g_{n s p}^{m(s)} \cos m \phi_{d}+h_{n s p}^{m(s)} \sin m \phi_{d}\right] \sin \left(\omega_{s} s t+\omega_{p} p t_{m}\right)\right\} \\
& \quad \text { for } r>a+h
\end{aligned}
$$

where $r$ is the radius, $\theta_{d}$ the dipole colatitude, $\phi_{d}$ the dipole longitude, $t$ (expressed in years) the season counted from January 1, at 00:00 universal time, $t_{m}$ (expressed in hours) the magnetic universal time, $N$ the so-called Wolf ratio, $F_{10.7}$ the solar radio flux index (expressed in solar flux units, or SFU, where $\left.1 \mathrm{SFU}=10^{-22} \mathrm{~W} \mathrm{~m}{ }^{-2} \mathrm{~Hz}^{-1}\right), a$ the mean Earth radius $(a=6371.2 \mathrm{~km}), P_{n}^{m}$ the Schmidt normalized associated Legendre function of degree $n$ and order $m, \omega_{s}=2 \pi \mathrm{rad} /$ year the fundamental angular frequency for seasonal variation, $\omega_{p}=2 \pi / 24 \mathrm{rad} / \mathrm{h}$ the fundamental angular frequency for diurnal variation, $s$ and $p$ the associated wavenumbers and $q_{n s p}^{m(c, s)}, s_{n s p}^{m(c, s)}, g_{n s p}^{m(c, s)}$ and $h_{n s p}^{m(c, s)}$ the model coefficients. The magnetic universal time is $t_{m}=\left(180-\phi_{d, s}\right) / 15$, where $\phi_{d, s}$ is the dipole longitude of the subsolar point (expressed in degrees).

The secondary field potential, $V_{2}$, takes everywhere the same form as $V_{1}$ in Eq. (3), but with a different set of model coefficients, $g_{n s p}^{\prime m(c, s)}$ and $h_{n s p}^{\prime m(c, s)}$. These coefficients are related to primary coefficients $q_{n s p}^{m(c, s)}$ and $s_{n s p}^{m(c, s)}$ through a transfer function that is best expressed by using complex spherical harmonics and associated complex model coefficients. Introducing $\boldsymbol{\epsilon}$, respectively $\boldsymbol{\iota}$, the vectors of complex coefficients analog to the $\left(q_{n s p}^{m(c, s)}\right.$, $\left.s_{n s p}^{m(c, s)}\right)$, respectively $\left(g_{n s p}^{\prime m(c, s)}, h_{n s p}^{\prime m(c, s)}\right)$, the following matricial equation relates primary and induced complex coefficients:

$$
\iota=Q \epsilon
$$

where $Q$ is a complex matrix describing the effect of mantle conductivity on each spatial and temporal harmonic of the primary field. Following Sabaka et al. (2002), only the highest frequency is considered when there is a diurnal-seasonal modulation. Also, there obviously is no induction for $p=0$ and $s=0$. As a result (and setting $p_{\min }=0$ as we assume in this study, see below), $\boldsymbol{Q}$ is a block diagonal matrix made of $s_{\max }-s_{\min }$ identical block diagonal matrices of the form

$$
\boldsymbol{Q}_{s \neq 0}=\left(\begin{array}{cc}
\boldsymbol{Q}_{p>0} & \mathbf{0} \\
\mathbf{0} & \boldsymbol{Q}_{p=0}
\end{array}\right)
$$

and one block diagonal matrix of the form

$$
\boldsymbol{Q}_{s=0}=\left(\begin{array}{cc}
\boldsymbol{Q}_{p>0} & \mathbf{0} \\
\mathbf{0} & \mathbf{0}
\end{array}\right)
$$

where the zero matrix in the lower right corner of $\boldsymbol{Q}_{s=0}$ has the same size as $\boldsymbol{Q}_{p=0}$. The $\boldsymbol{Q}_{p>0}$ matrix describes the induction effect on each (nonzero) diurnal harmonic and is the same for all $s$ values. The $\boldsymbol{Q}_{p=0}$ matrix describes the induction effect on nonzero seasonal harmonics when $p=0$.

Expressing the continuity of the radial component of the field through the current sheet at altitude $h$ leads to another matricial relationship between the $\left(q_{n s p}^{m(c, s)}, s_{n s p}^{m(c, s)}\right)$ and $\left(g_{n s p}^{m(c, s)}, h_{n s p}^{m(c, s)}\right)$ coefficients. Specifically, we have that

$$
g_{n s p}^{m(c, s)}=-\left(\frac{n}{n+1}\right)\left(\frac{a+h}{a}\right)^{2 n+1} q_{n s p}^{m(c, s)}
$$

and the same relationship between $h_{n s p}^{m(c, s)}$ and $s_{n s p}^{m(c, s)}$.

The DIFI algorithm solves for the $\left(q_{n s p}^{m(c, s)}, s_{n s p}^{m(c, s)}\right)$ coefficients, from which the other coefficients can be derived. In order to further reduce the size of the model vector, the inversion was performed in the QD coordinate system, using the same QD basis functions as Sabaka et al. (2002). The transformation from dipole to QD coefficients involves a matrix that was precomputed during the development phase (see Figure 2 in Chulliat et al. 2013).

In the present modeling work, we took $N=14.85 \times 10^{-3} \mathrm{SFU}^{-1}$, as previously determined by Sabaka et al. (2002) (using the technique of Olsen 1993) from observatory data, and we used daily observed values of $F_{10.7}$ for all datasets. The maximum degree and order were set to $N_{\max }=60$ and $M_{\max }=12$, the minimum/maximum diurnal wavenumbers to $p_{\min }=0$ and $p_{\max }=4$, and the minimum/ maximum seasonal wavenumbers to $s_{\min }=-2$ and $s_{\max }=2$. As a result, the total number of real coefficients for each pair of wavenumbers $(p, s)$ is $2 N_{d}=$ $2\left[M_{\max }\left(M_{\max }+2\right)+\left(N_{\max }-M_{\max }\right)\left(2 M_{\max }+1\right)\right]=2736$, 
where the factor 2 accounts for the cosine and sine coefficients. The total number of wavenumber pairs is $N_{s p}=\left(p_{\max }-p_{\min }+1\right)\left(s_{\max }-s_{\min }+1\right)=25$. The maximum degree and order of the QD model coefficients used for the inversion were set to $K_{\max }=45$ and $L_{\max }=5$, leading to a total of $N_{q}=L_{\max }\left(L_{\max }+2\right)+\left(K_{\max }-L_{\max }\right)\left(2 L_{\max }+1\right)=475$ complex coefficients for each wavenumber pair.

We used two different $\boldsymbol{Q}_{p>0}$ matrices, both of them calculated by Alexei Kuvshinov (ETH Zürich). The first one was derived from a conductivity model with a surface shell of laterally variable conductance compiled by Manoj et al. (2006a) and a 1D conductivity profile underneath taken from Kuvshinov and Olsen (2006). (This is the matrix used in the development phase, see Olsen et al. 2013). The second one was derived more recently from the same surface shell and a 1D profile derived from 10 years of satellite data by Püthe et al. (2015). The surface shell describes nonuniform conductivities of oceans and continents. As a result of the use of a non-1D conductivity profile, the $\boldsymbol{Q}_{p>0}$ matrix is dense. We otherwise used the same $\boldsymbol{Q}_{p=0}$ matrix as Sabaka et al. (2002), assuming an insulating mantle in the region $a-\delta \leq r \leq a$, where $\delta=1000 \mathrm{~km}$, and a superconducting mantle in the region $r<a-\delta$.

\section{Inversion}

The DIFI models were obtained by minimizing the following objective function:

$$
\begin{gathered}
\Phi(\boldsymbol{m})=[\boldsymbol{\gamma}-\boldsymbol{f}(\boldsymbol{m})]^{T} \boldsymbol{C}_{e}^{-1}[\boldsymbol{\gamma}-\boldsymbol{f}(\boldsymbol{m})]+\lambda_{1} \boldsymbol{m}^{T} \boldsymbol{C}_{1}^{-1} \\
\boldsymbol{m}+\lambda_{2} \boldsymbol{m}^{T} \boldsymbol{C}_{2}^{-1} \boldsymbol{m}
\end{gathered}
$$

where $\boldsymbol{\gamma}$ is the data vector, $\boldsymbol{m}$ the model vector in quasidipole coordinates, $\boldsymbol{f}(\boldsymbol{m})$ the data estimate vector calculated from the model, $\boldsymbol{C}_{e}$ the data covariance matrix, $\lambda_{1}$ and $\lambda_{2}$ damping parameters and $C_{1}$ and $C_{2}$ regularization matrices. Because all data are vector data, $\boldsymbol{f}$ is linear and the data estimate vector may be expressed as $\boldsymbol{f}(\boldsymbol{m})=\boldsymbol{G} \boldsymbol{m}$. The least-square estimate is then

$$
\tilde{\boldsymbol{m}}=\left(\boldsymbol{G}^{T} \boldsymbol{C}_{e}^{-1} \boldsymbol{G}+\lambda_{1} \boldsymbol{C}_{1}^{-1}+\lambda_{2} \boldsymbol{C}_{2}^{-1}\right)^{-1} \boldsymbol{G}^{T} \boldsymbol{C}_{e}^{-1} \boldsymbol{\gamma} .
$$

The $C_{1}$ regularization matrix is the identity matrix; it equally damps all coefficients (in quasi-dipole coordinates) and minimizes the noise in the final model estimate. The $\boldsymbol{C}_{2}$ matrix was built from the following norm:

$$
\begin{aligned}
Q_{2} & =\int_{0}^{T} \int_{\Omega}\left\|\nabla_{S}^{2} \boldsymbol{J}_{e q}\left(\theta_{d}, \phi_{d}, t_{m}\right)\right\|^{2} \sin ^{8}\left(2 \theta_{d}\right) d \Omega d t_{m} \\
& \times\left(\int_{0}^{T} \int_{\Omega} \sin ^{8}\left(2 \theta_{d}\right) d \Omega d t_{m}\right)^{-1}
\end{aligned}
$$

where $T$ is set to 1 year, $\Omega$ is the unit sphere, $\nabla_{S}^{2}$ is the surface Laplacian and $\boldsymbol{J}_{e q}$ is the equivalent current density at altitude $h$ associated with model $\boldsymbol{m}$. It is almost identical to the smooth ionospheric E-region current norm used in Sabaka et al. (2002, section 4.1.3), except that it is not restricted to the $p>0$ coefficients. The $Q_{2}$ norm measures the roughness of the equivalent currents at all local times. The $\sin ^{8}\left(2 \theta_{d}\right)$ function takes values close to one at mid-latitudes and close to zero in the equatorial region (and at high latitudes), so that the equatorial electrojet does not contribute to the norm. The equivalent current density may be expressed as

$$
\boldsymbol{J}_{e q}\left(\theta_{d}, \phi_{d}, t, t_{m}\right)=-\hat{\boldsymbol{r}} \times \nabla \Psi_{1}
$$

where $\hat{\boldsymbol{r}}$ is the unit radial vector and

$$
\begin{aligned}
\Psi_{1}\left(\theta_{d}, \phi_{d}, t, t_{m}\right) \\
=\left(1+N \times F_{10.7}\right) \\
\quad\left(-\frac{1}{\mu_{0}}\right) \sum_{s=s_{\min }}^{s_{\max }} \sum_{p=p_{\min }}^{p_{\max }} \sum_{n=1}^{N_{\max }} \sum_{m=0}^{M_{\max }} a\left(\frac{a+h}{a}\right)^{n} P_{n}^{m}\left(\theta_{d}\right)\left(\frac{2 n+1}{n+1}\right) \\
\quad\left\{\left[q_{n s p}^{m(c)} \cos m \phi_{d}+s_{n s p}^{m(c)} \sin m \phi_{d}\right] \cos \left(\omega_{s} s t+\omega_{p} p t_{m}\right)\right. \\
\left.\quad+\left[q_{n s p}^{m(s)} \cos m \phi_{d}+s_{n s p}^{m(s)} \sin m \phi_{d}\right] \sin \left(\omega_{s} s t+\omega_{p} p t_{m}\right)\right\}
\end{aligned}
$$

is a current function defined on the sphere of radius $r=a+h$. When calculating the $C_{2}$ matrix, we neglected the time variations of the solar radio flux index and set it to zero in Eq. (10).

The data covariance matrix was taken diagonal, with the same variance of $2.25^{2} \mathrm{nT}^{2}$ for satellite and observatory data. We tested several values of the damping parameters and found the best compromise between misfit and roughness (according to the $L$-curve criterion) for $\lambda_{1}=10^{4}$ and $\lambda_{2}=10^{-17}$. For these parameters, the resolving strength of the first, respectively second, norm was found to be $14.4 \%$, respectively $62.5 \%$, of the total number of (complex) coefficients in the most recent model presented below.

\section{Results}

The initial model distributed by ESA as the official DIFI level 2 product (version 0101), hereafter referred to as DIFI-2015a, was obtained from satellite data until May 31,2015 , and the same $Q$ matrix as used during the development phase (see "Model parameterization" section). Here we present a more recent model, hereafter referred to as DIFI-2015b, calculated from satellite data until July 17, 2015, and using the most recent $\boldsymbol{Q}$ matrix calculated by A. Kuvshinov (see "Model parameterization" section). 


\section{Residual statistics and data fits}

The residual statistics of the DIFI-2015b model are given in Table 1, sections (a) and (b). For satellite data, the mean residuals are very small (generally less than $1 \mathrm{nT}$ ) for all components, indicating the absence of unmodeled bias in the data. The root-mean-square (RMS) errors are slightly larger for Swarm A, which could be due to the lower altitude of Swarm A compared with Swarm B. For both satellites, the RMS errors are larger for the polar and azimuthal components $B_{\theta}$ and $B_{\phi}$ than for the radial component $B_{r}$. This probably reflects the effect of interhemispheric field-aligned currents (IHFACs) on the magnetic field recorded at satellite altitude, as recently observed by Lühr et al. (2015) in Swarm data. Such currents can be large, especially during summer and winter seasons when Sq currents of different intensities flow in the northern and southern hemispheres. The effect of IHFACs is attenuated on the ground; hence, similar RMS errors were obtained for the three components when considering all observatory data. On average, RMS errors for satellite and observatory data are of the same order of magnitude, which supports our choice of using the same variances for both types of data.

Mean residuals for individual observatories (Fig. 3, top) take larger absolute values than the mean over all observatories, reflecting the smaller amount of data and some level of spatial variability that is averaged out when considering a large number of observatories. The largest mean residuals are found near the Southern auroral region, suggesting that large, non-Sq ionospheric fields are contaminating the observatory records there during geomagnetically quiet times. Elsewhere, there is no clear pattern in the evolution of mean residuals with respect to QD latitude. RMS residuals (Fig. 3, bottom) are found to be largest near the dip equator, especially at Huancayo (HUA, Peru) for the polar component [see also the values in Table 1, section (b)]. This is probably due to the larger diurnal variations, mostly on the polar component, generated by the equatorial electrojet. Another factor could be that HUA is located in South America, where the magnetic dip equator is maximally inclined with respect to the geographic equator, and is the only observatory in this area (Fig. 2). Overall the RMS residuals are larger in the Southern hemisphere, perhaps because of the smaller density of observatories there. The abnormally large RMS residual at EYR on the azimuthal component (blue circle close to $15 \mathrm{nT}$ in Fig. 3, bottom) is probably due to the proximity of the auroral zone. Observatories with the smallest RMS residuals are all located between $20^{\circ}$ and $55^{\circ} \mathrm{QD}$ latitudes.

Figure 4 shows how the model fits the data from the Chambon-la-Forêt (CLF, France) observatory. CLF is a mid-latitude observatory in the Northern hemisphere, generally to the North of the focus of the Sq current system, hence the positive variations (on average) on the $B_{\theta}$ component. We check that, during quiet times, the model reproduces the average variations on the three components. The largest departures from the model are caused by the unmodeled day-to-day variations of the Sq field. These contribute to the largest part of the RMS residuals given in Table 1, section (b). On disturbed days (shown with a gray background), non-Sq variations cause further departures from the model, for example on MJD2000 $=5190(\mathrm{MJD} 2000$ being referenced to January 1, 2000 at $00 \mathrm{UT})$.

The data fit for HUA is shown in Fig. 5, and corresponding mean and RMS residuals are provided in

Table 1 (a), (b) Mean $(\mu)$ and root-mean-square $(\sigma)$ residuals (in $\mathrm{nT}$ ) of the DIFI-2015b model in the domain of validity, $\left|\theta_{q d}\right| \leq 55^{\circ}$, for the radial $(r)$, polar $(\theta)$ and azimuthal $(\phi)$ components. (c) Mean and root-mean-square differences (in $\mathrm{nT}$ ) between predictions of the DIFI-2015b model and independent observations at the NCK and CBI observatories during quiet times (as defined for this study, see "Data preprocessing" section), for the same components

\begin{tabular}{|c|c|c|c|c|c|c|c|}
\hline & $N$ & $\mu_{r}$ & $\sigma_{r}$ & $\mu_{\theta}$ & $\sigma_{\theta}$ & $\mu_{\phi}$ & $\sigma_{\phi}$ \\
\hline \multicolumn{8}{|c|}{ (a) Satellites } \\
\hline$A \& B$ & 347,686 & -0.21 & 4.58 & -0.50 & 7.16 & -1.01 & 10.46 \\
\hline A & 158,379 & -0.16 & 4.61 & -0.18 & 7.25 & -1.48 & 10.67 \\
\hline B & 189,307 & -0.25 & 4.54 & -0.77 & 7.05 & -0.61 & 10.16 \\
\hline \multicolumn{8}{|c|}{ (b) Observatories } \\
\hline All & 242,485 & -0.03 & 6.05 & 0.13 & 7.45 & 0.02 & 7.06 \\
\hline CLF & 2817 & -0.82 & 4.59 & -0.10 & 4.91 & -0.60 & 4.81 \\
\hline HUA & 4747 & -1.35 & 7.66 & -2.52 & 18.00 & 2.57 & 9.04 \\
\hline \multicolumn{8}{|c|}{ (c) Observatories } \\
\hline NCK & 4255 & -1.34 & 3.88 & 0.94 & 6.37 & 0.14 & 5.47 \\
\hline CBI & 4248 & 0.96 & 6.12 & -4.93 & 8.28 & 0.24 & 8.33 \\
\hline
\end{tabular}



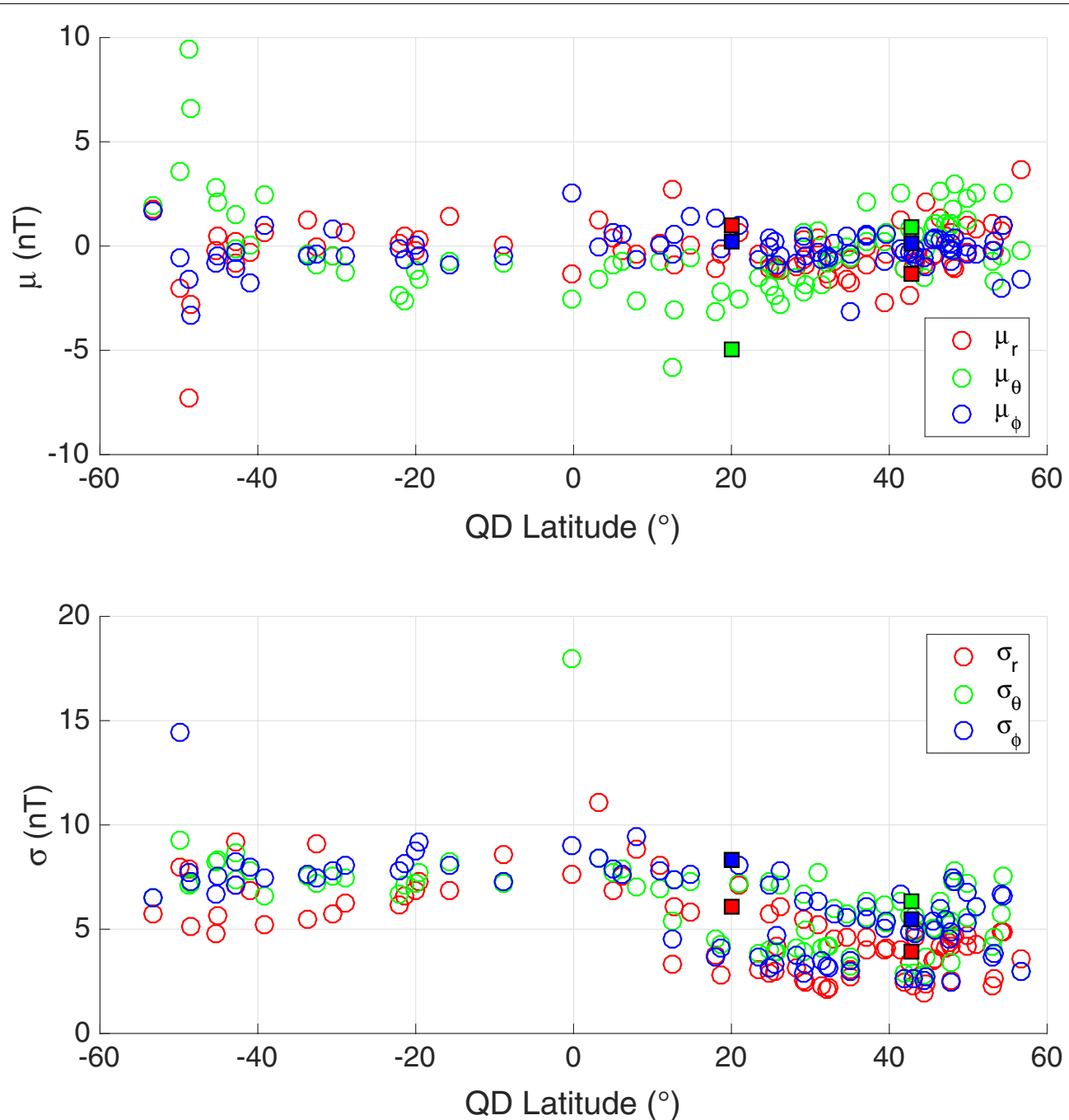

Fig. 3 Mean $(\mu$, top) and root-mean-square $(\sigma$, bottom) residuals (in nT) of the DIFI-2015b model for individual observatories and for the radial $(r)$, polar $(\theta)$ and azimuthal $(\phi)$ components, as a function of quasi-dipole latitude. The mean and root-mean-square differences between DIFI-2015b predictions and independent observations at NCK and CBI during quiet times (as defined for this study) are also shown as filled squares with the same color code

Table 1, section (b). Due to the equatorial electrojet, the recorded ionospheric variations are significantly larger than at mid-latitudes. However, the model reproduces the electrojet field variations very well on the $B_{\theta}$ component, where the amplitude reaches more than $150 \mathrm{nT}$ during the considered time interval. Variations are less regular on the other components, but the model captures the average behavior.

\section{Validation using independent data}

At the time of the model calculation, we used all ground and satellite magnetic data available in order to come up with the best possible solution. Since then, however, data from two observatories, Chichijima (CBI, Japan) and
Nagycenk (NCK, Hungary), were added on the Swarm level 2 project server (see Fig. 2 for their locations). We used these data to provide an independent validation of the model. As shown in Table 1 and Fig. 3, top, the RMS differences are of the same order of magnitude as the ones obtained for all the observatory data used in the model (see Table 1). This suggests that the model correctly predicts the main features of the Sq field variations, even away from the observatories used in the inversion. As an illustration, Fig. 6 shows 6 days of model predictions compared with CBI observations (corrected in the same way as the observatory data used in the model). The model correctly predicts the negative variations on the $B_{\theta}$ component, which are characteristic of a mid-latitude 

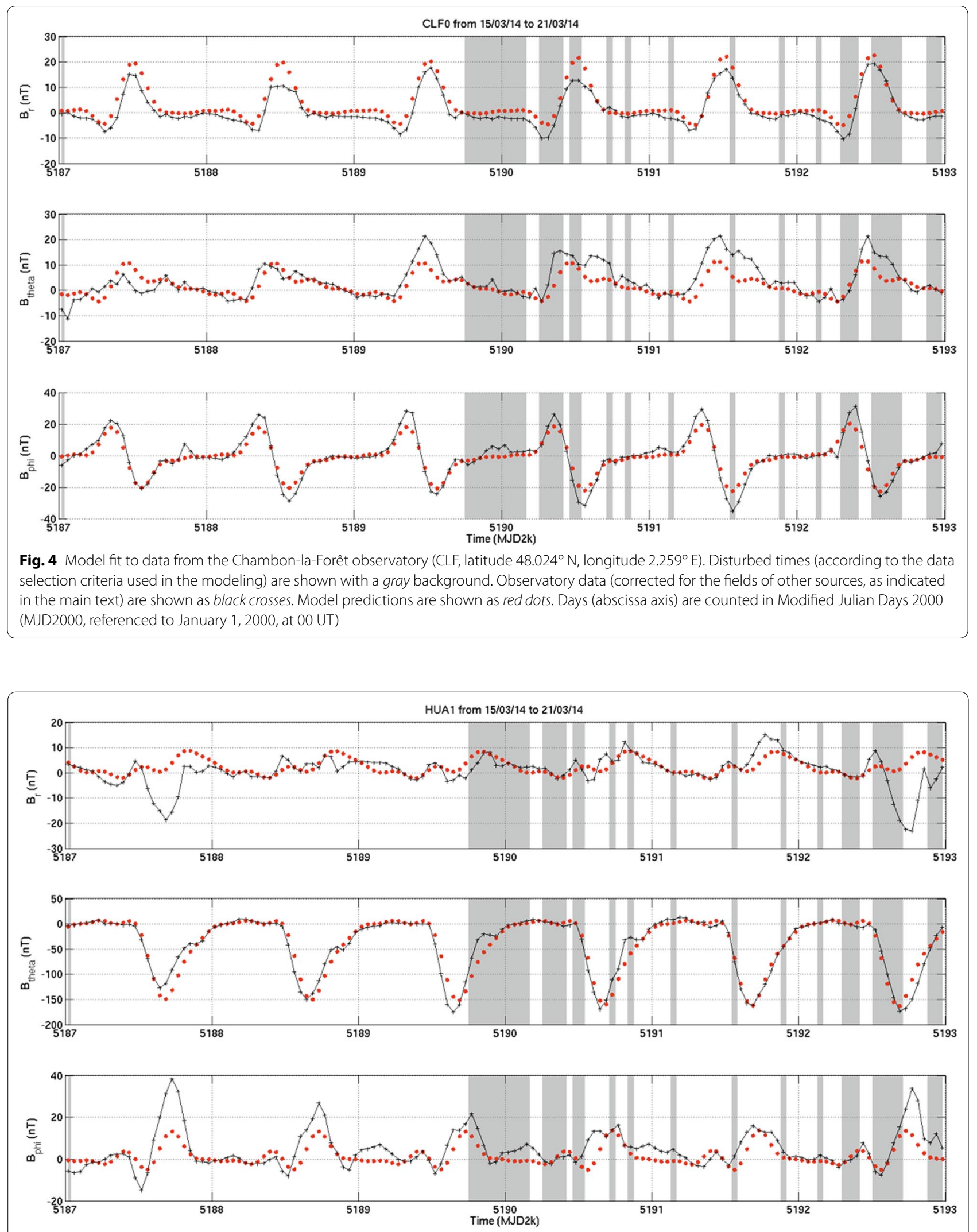

Fig. 5 Same as Fig. 4 for the Huancayo observatory (HUA, latitude $12.045^{\circ}$ S, longitude $75.340^{\circ} \mathrm{W}$ ) 


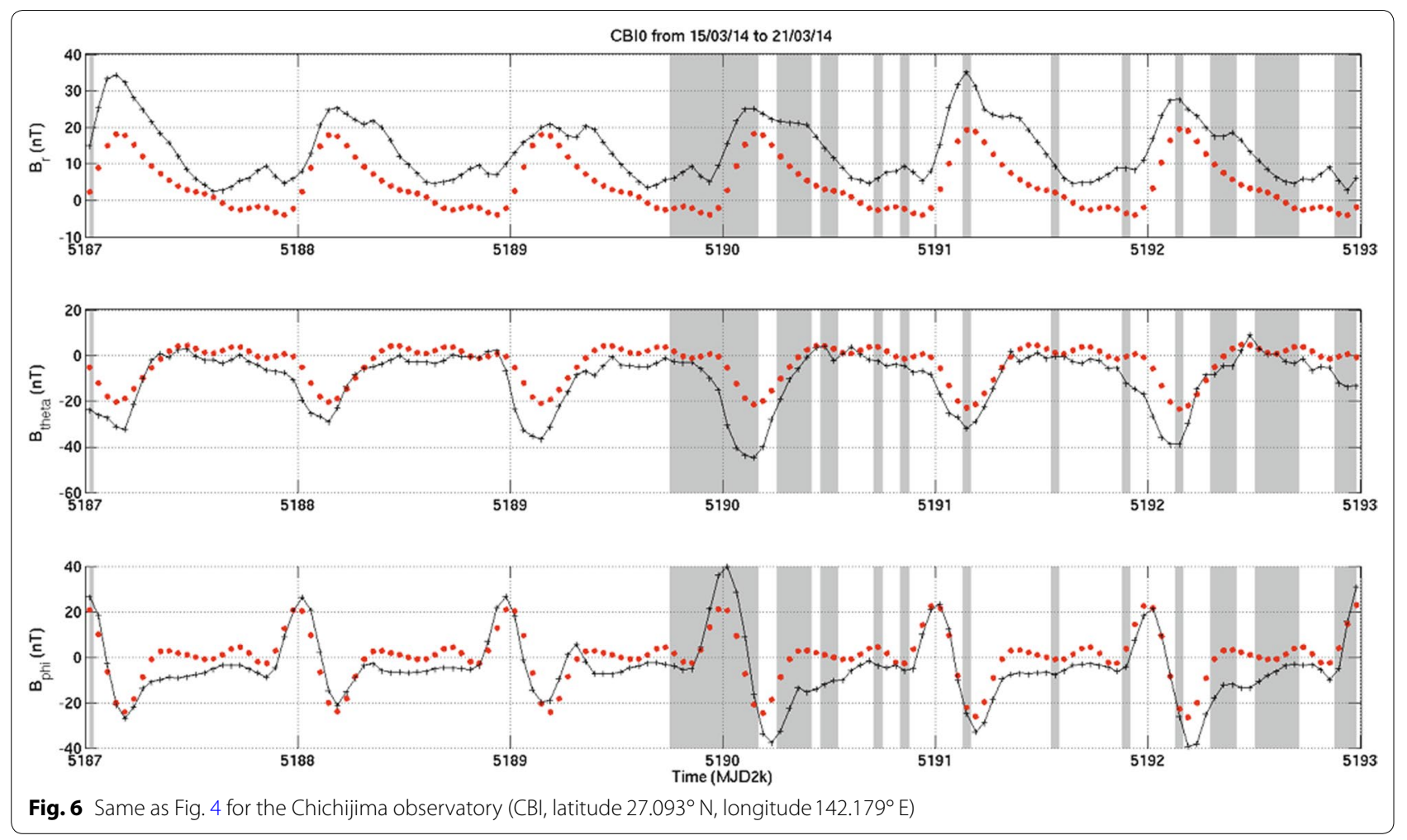

observatory located to the South of the Sq current focus in the Northern hemisphere. The mean differences for CBI and NCK are also very similar to the ones obtained at nearby observatories used in the inversion, except at CBI for the $B_{\theta}$ component (Fig. 3, bottom). This could perhaps be explained by the fact that $\mathrm{CBI}$ is more remote from other observatories than NCK (see Fig. 2).

\section{Model spectra}

For each pair of wavenumbers $(p, s)$ and each type of field (primary or secondary), it is possible to calculate two power spectra from the subsets of coefficients $\left(q_{n s p}^{m(c)}\right.$, $\left.s_{n s p}^{m(c)}\right)$ and $\left(q_{n s p}^{m(s)}, s_{n s p}^{m(s)}\right)$. As there are 25 pairs of wavenumbers, this yields 100 spectra for altitudes between the ground and the ionosphere, and another $100 \mathrm{spec}-$ tra above the ionosphere. Figure 7 shows ten of these spectra at altitude $h=0$, for $\left(q_{n s p}^{m(s)}, s_{n s p}^{m(s)}\right)$ with $s=1$ and $p=0$ to 4 . For the primary field, the first three degrees for $p=1$ and the second and third ones for $p=2$ have the largest powers. The $p=1$ and $p=2$ harmonics are dominant at all degrees. There is a plateau around degrees 30-40 where the $p=3$ and $p=4$ become more energetic and their power becomes closer to that of the $p=1$ and $p=2$ harmonics. This spatial scale corresponds to the equatorial electrojet. The $p=0$ term is not negligible but has a power smaller than that of the leading harmonics.
As expected, the induced field has less energy than the primary field at all degrees. The induced $p=0$ term decreases sharply after $n=4$, reflecting the much smaller induction effect for that term due to the slower $(s=1)$ time variations. The induced counterpart of the equatorial electrojet for $s=1$ is found to be about ten times less energetic. Similar results were found for the other $s$ and sine/cosine values (not shown).

\section{Equivalent current systems}

Maps of the normalized equivalent current function $\Psi_{1}$ at different universal times and seasons (Figs. 8, 9, 10, 11) provide a convenient way to visualize the DIFI model and its temporal evolution. As expected, the Sq current system is made of two vortices separated by the magnetic dip equator, one counterclockwise in the Northern hemisphere and the other clockwise in the Southern hemisphere. The two vortices rotate around the Earth during the day, always facing the Sun, and there is very little current on the nightside. The current density (which is proportional to the local gradient of $\Psi_{1}$ ) is largest along the dip equator, i.e., in the EEJ region. The seasonal variation of the Sq current system is clearly visible: In the Northern hemisphere, the currents are generally strongest in the summer (July 1 ) and weakest in the winter (January 1 ), with some intermediate values in the spring (April 1) and fall (October 1). (Note that here and in what follows, 


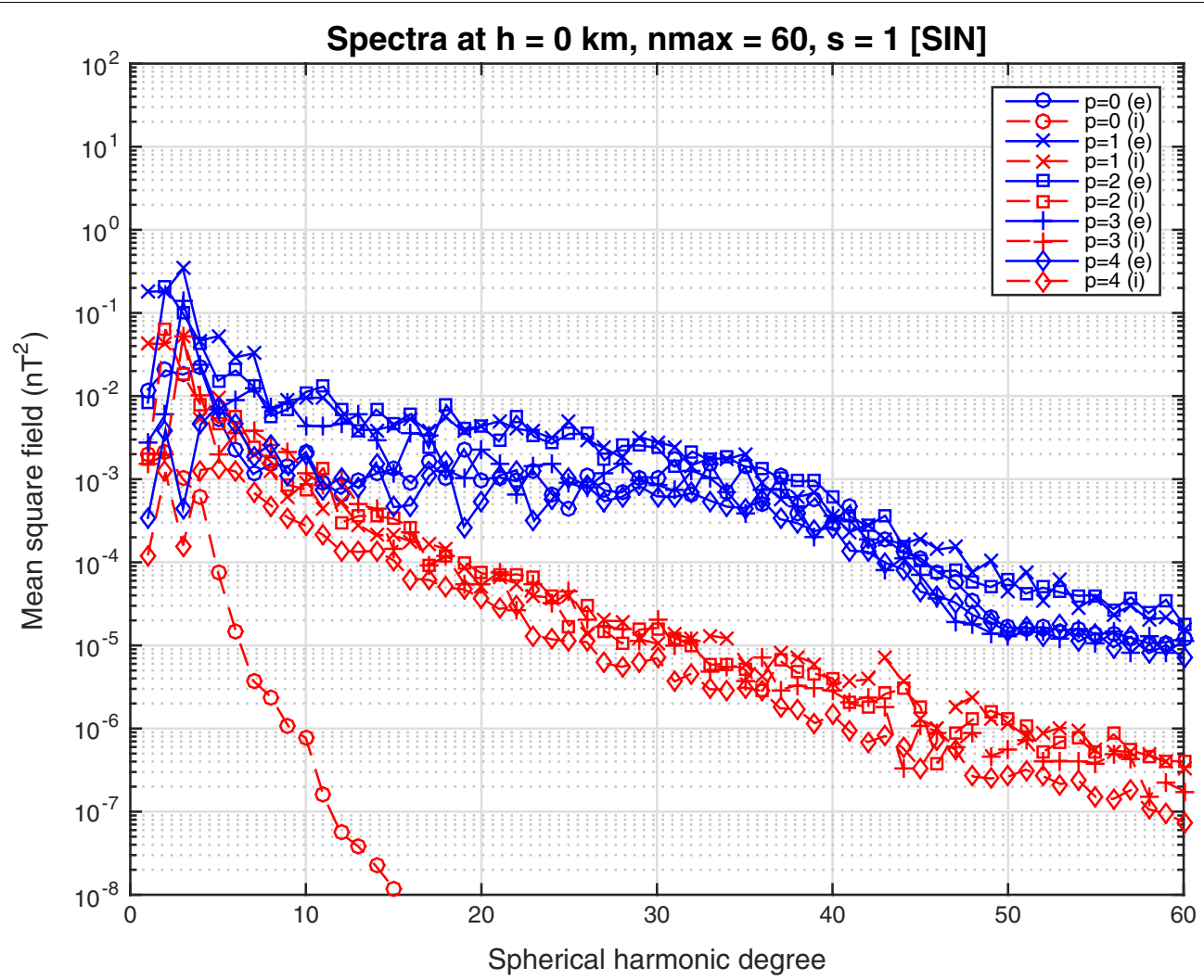

Fig. 7 Power spectra at altitude $h=0 \mathrm{~km}$ of the subsets of DIFI sine coefficients corresponding to $s=1$ and $p=0$ to 4 . Primary, respectively secondary (induced), fields are shown in blue, respectively red

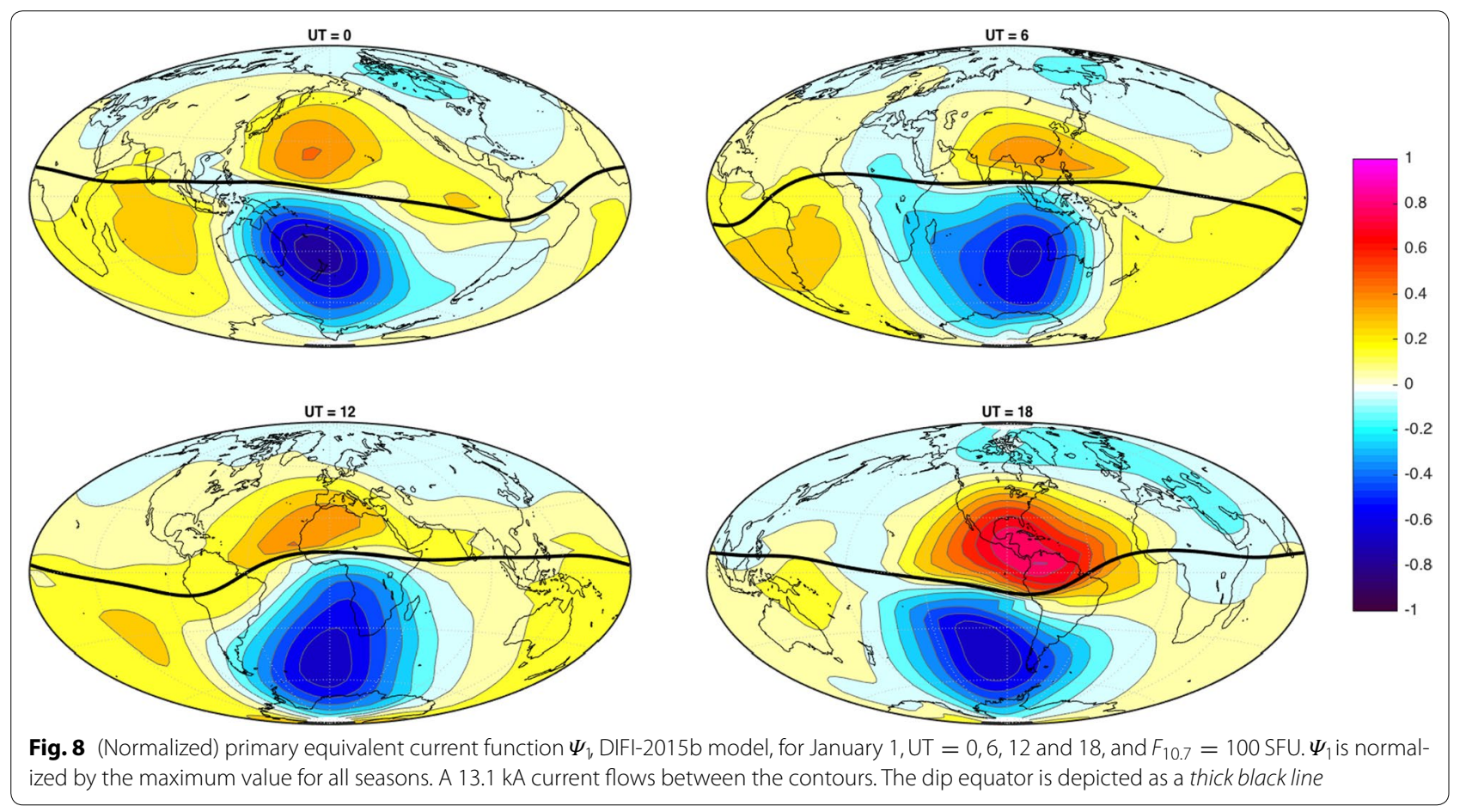



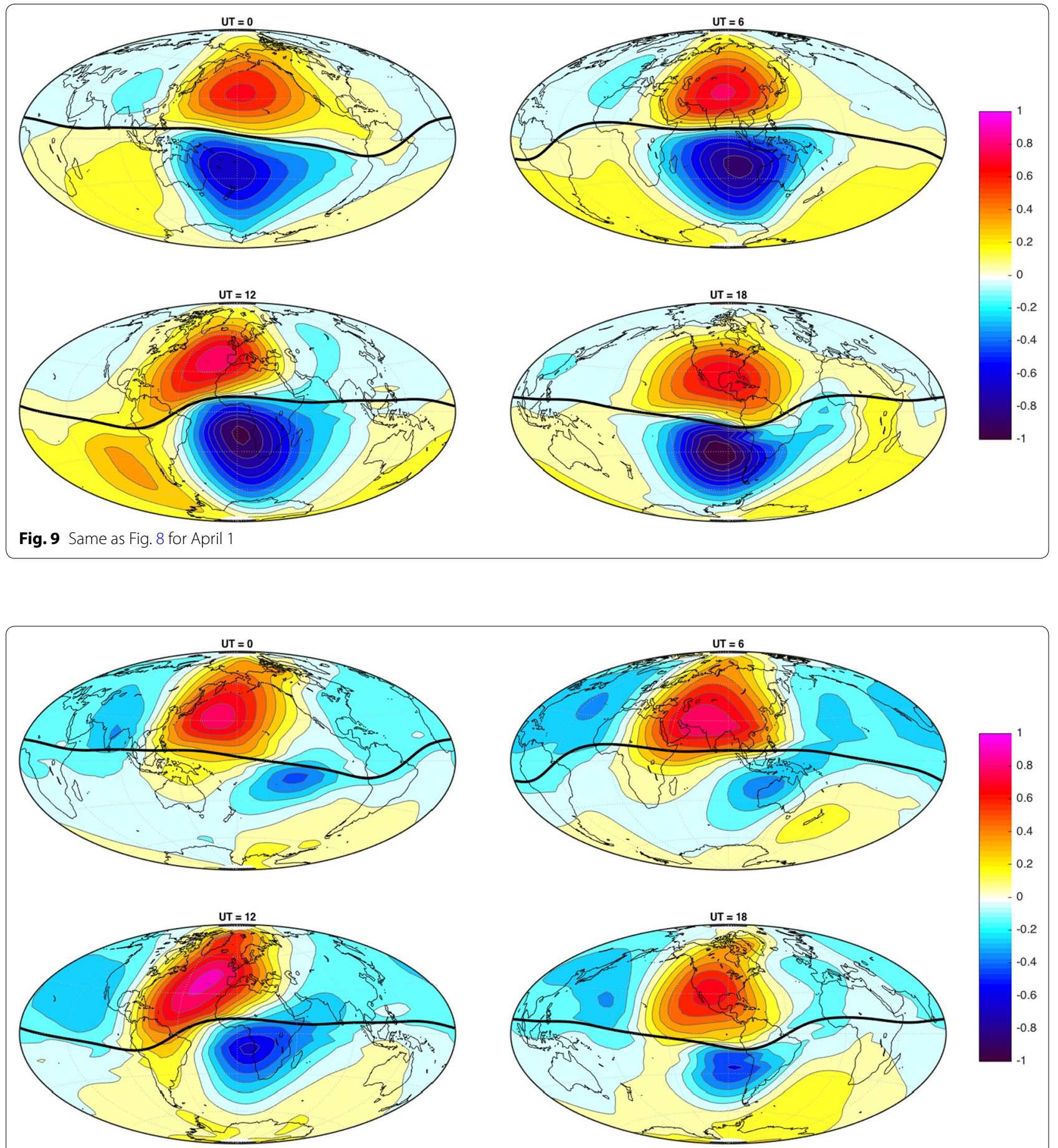

Fig. 10 Same as Fig. 8 for July 1

we only use Northern hemisphere season names, except noted otherwise.)

In Fig. 12, we plot the evolution with UT and season of the maximum absolute value of $\Psi_{1}$ in each hemisphere, hereafter denoted as $\Psi_{N}$ (Northern hemisphere) and $\Psi_{S}$
(Southern hemisphere). $\Psi_{N}$ and $\Psi_{S}$ are the total currents flowing in the dayside vortex in each hemisphere. These plots reveal several interesting characteristics of the Sq seasonal variability. First, although on average over all $\mathrm{UT}, \Psi_{N}$ is smallest in the winter, for UT between 16 and 

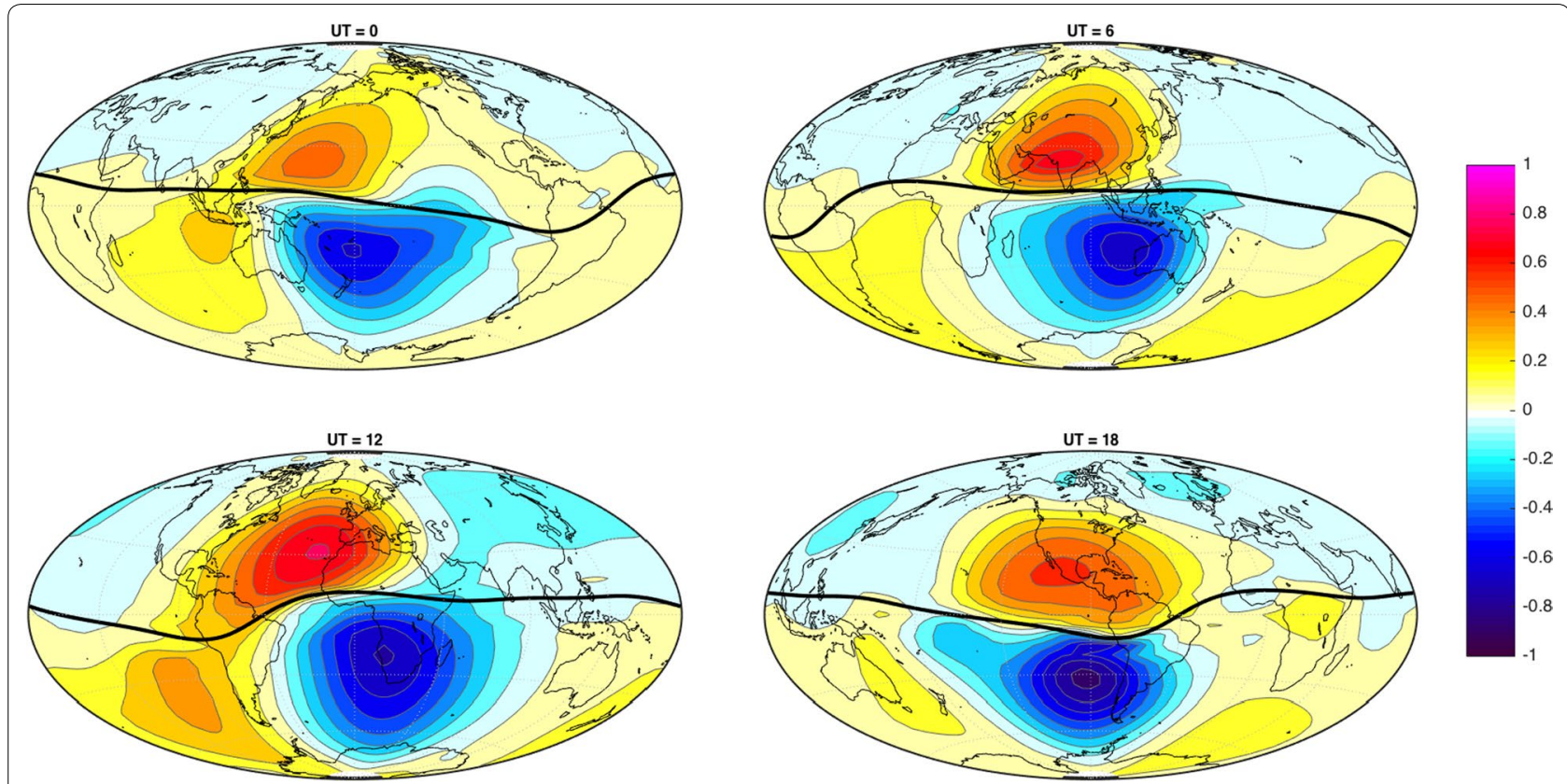

Fig. 11 Same as Fig. 8 for October 1

$21 \Psi_{N}$ is actually larger in the winter than in any other season. In the Southern hemisphere, $\Psi_{S}$ takes its largest values during the spring, for nearly all UT. This is shown in Fig. 9. The winter values, instead of being the largest, are often close to the fall values. As expected, summer values are the smallest nearly all the time. Second, there is a significant seasonal asymmetry between spring and fall, i.e., the Sq currents are not identical in both seasons despite a similar amount of heating coming from the Sun. This asymmetry was previously noted in observatory data (Chulliat et al. 2005), but the Swarm-based DIFI model shows that it is a global feature and that it is especially strong in the Southern hemisphere.

The main field has a strong effect on the shape of the Sq current system. This is most clearly seen when the Sq current system passes over the Americas (UT around 16-17), where the dip equator is bended with respect to the geographic equator. The current strength is also affected by the main field, as shown in Fig. 12. The current strength raises sharply over the Americas in the winter in the Northern hemisphere, although it is not clear why this happens only in the winter. In the Southern hemisphere, the total current increases in all seasons over Americas and takes its maximum values there except in the Southern winter.

Another effect of the main field is shown in Fig. 13, where the difference between the LT of the current system focus and noon is plotted for all seasons. In the Northern hemisphere, when the current system passes over America, its westward drift speed is reduced and the LT of its focus increases. In the winter, the current focus switches from a situation where it was leading the noon meridian to one where it is usually slightly trailing behind it. A similar but reverse effect occurs in the Southern hemisphere between 15 and 17 UT. The fact that this effect is observed at all seasons suggests that it is caused by the dip equator bending in the American sector. The sudden change in the focus LT can also be seen in maps of the equivalent current function between 14 and 18 UT (not shown).

Figures 10 and 13 also show that the current system in the Northern hemisphere leads the one in the Southern hemisphere by up to 3 or even $4 \mathrm{~h}$ in the summer. The reverse happens in the winter, when the current system in the Southern hemisphere is slightly ahead of the one in the Northern hemisphere. This is compatible with earlier results from observatory data obtained by, e.g., Matsushita and Maeda (1965). Our analysis suggests that the Northern hemisphere current system also slightly leads in the spring and fall.

Coming back to Fig. 12, we note that the strength of the current systems is modulated in longitude. There are four minima in the Southern hemisphere, approximately every $90^{\circ}$ (6-h UT), which is reminiscent of the wave- 4 structure observed in the CHAMP-derived EEJ signal. This structure was shown to be related to the DE3 non-migrating tide that is excited by deep convection in the tropical troposphere (Lühr et al. 2012). However, no 

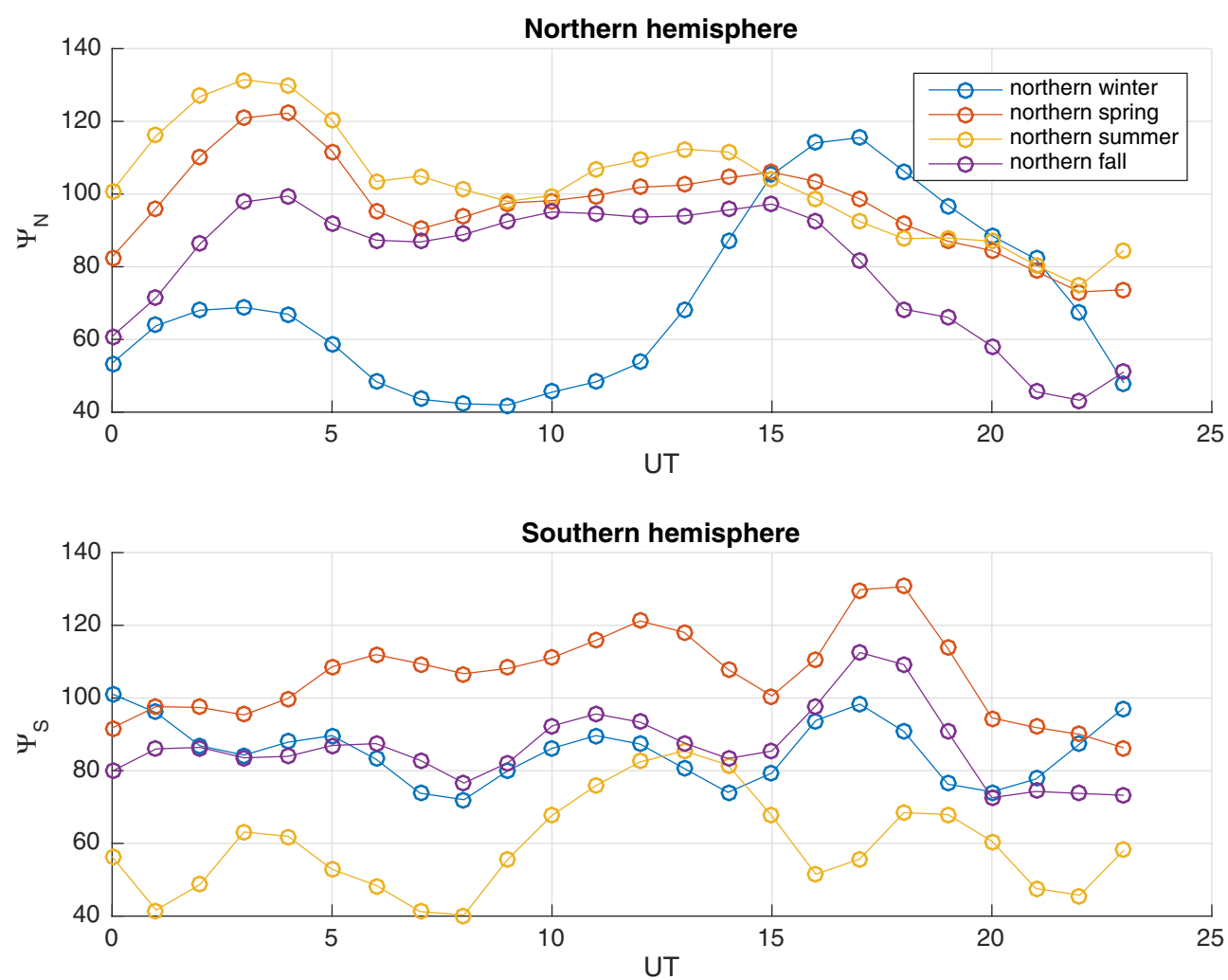

Fig. 12 Evolution with UT and season of the maximum absolute value of the primary current function $\Psi_{1}$ in the Northern $\left(\Psi_{N}\right)$ and Southern $\left(\Psi_{S}\right)$ hemispheres. $\Psi_{N}$ and $\Psi_{S}$ represent the total currents (in kA) flowing in the dayside vortex for each hemisphere. $F_{10.7}=100 \mathrm{SFU}$

such structure is observed in the Northern hemisphere, where the effect of the main field is dominant. Reasons for this hemispheric asymmetry could be that: (a) Some electrical currents flow from the equatorial region into the Southern hemisphere, i.e., there is some electrical coupling between the EEJ and Sq currents in that hemisphere; (b) part of the DE3 tide or another tide contributing to the equatorial wave- 4 structure leaks into the Southern hemisphere. In both cases, there seems to be the need for some coupling between EEJ and Sq currents, an issue that is still open (see, e.g., Bhardwaj et al. 2015; Manoj et al. 2006b, who presented the opposite view, and references therein).

The coupling hypothesis is supported by the larger bumps in the non-winter $\Psi_{N}$ curves at UT between 0 and 15 , corresponding to longitudes where the dip equator is in the Northern hemisphere and to seasons when the Sq current system is largest and most prone to interact with the EEJ. Conversely, the only bump in the winter $\Psi_{N}$ curve is found in the American sector, where the northern vortex gets partially enclosed by the bended dip equator in that sector (Fig. 8). In the Southern hemisphere, the largest $\Psi_{S}$ bumps are found in the American sector, where the dip equator goes deep into the that hemisphere. The more intense current in the Spring could also be explained by some coupling with the EEJ, as the EEJ strength is largest at equinoxes (e.g., Matsushita and Maeda 1965; Stening 1995).

\section{Induced field}

The induced Sq and EEJ fields at ground can also be represented by equivalent currents formally assumed to flow at Earth's surface $(r=a)$. A stream function for such currents may be expressed as

$$
\begin{aligned}
& \Psi_{2}\left(\theta_{d}, \phi_{d}, t, t_{m}\right) \\
&=\left(1+N \times F_{10.7}\right) \\
&\left(\frac{1}{\mu_{0}}\right) \sum_{s=s_{\min }}^{s_{\max }} \sum_{p=p_{\min }}^{p_{\max }} \sum_{n=1}^{N_{\max }} \sum_{m=0}^{M_{\max }} a P_{n}^{m}\left(\theta_{d}\right)\left(\frac{2 n+1}{n}\right) \\
&\left\{\left[g_{n s p}^{\prime m(c)} \cos m \phi_{d}+h_{n s p}^{\prime m(c)} \sin m \phi_{d}\right] \cos \left(\omega_{s} s t+\omega_{p} p t_{m}\right)\right. \\
&\left.+\left[g_{n s p}^{\prime m(s)} \cos m \phi_{d}+h_{n s p}^{\prime m(s)} \sin m \phi_{d}\right] \sin \left(\omega_{s} s t+\omega_{p} p t_{m}\right)\right\}
\end{aligned}
$$

with the same notations as in "Model parameterization" and "Inversion" sections. (Equations 12 and 13 were 

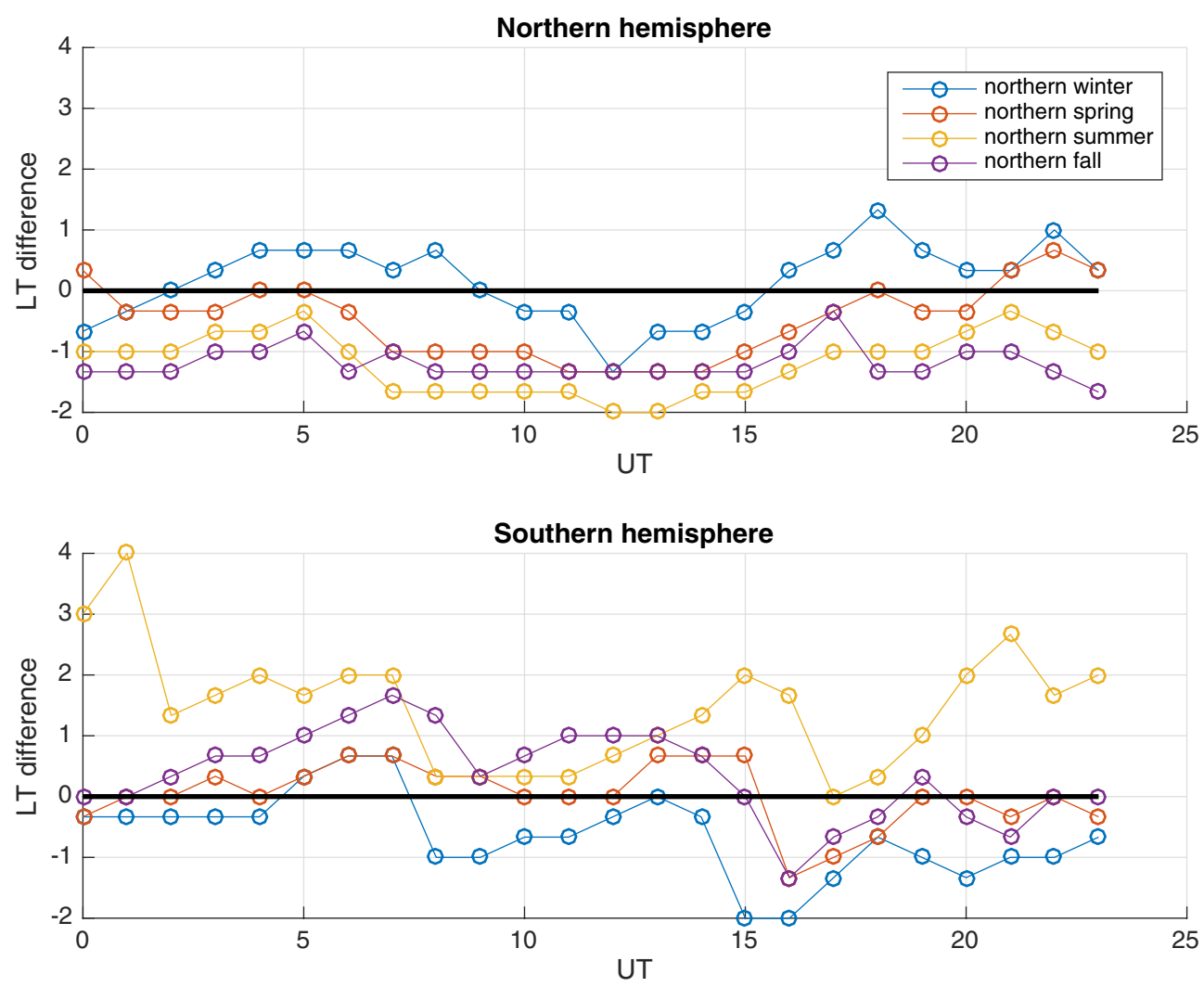

Fig. 13 Evolution with UT and season of the difference between the LT of the current system focus (defined as the point where the current function $\Psi_{1}$ takes its maximum absolute value) and noon in each hemisphere. A positive value indicates that the current system is trailing behind the noon meridian, while a negative value indicates that it is leading it. $F_{10.7}=100 \mathrm{SFU}$

derived from Chapman and Bartels 1940, chapter XVII.) Figure 14 shows such currents in the spring (April 1). Induced currents have a maximum for all seasons that is about half that of primary currents. They reach their largest values above the oceans (see, e.g., UT $=18$ in the Southern hemisphere), as expected due to the much larger conductivity there in the surface shell used to calculate the $\boldsymbol{Q}$ matrix. Induced currents are markedly less intense over large continental regions, especially Eurasia (see the UT $=6$ map).

When comparing primary (Fig. 9) and induced (Fig. 14) current systems, one notices that the induced field generally leads the primary field, by up to $1-2 \mathrm{~h}$. A similar result was recently found by Sabaka et al. (2015) in their pre-Swarm Comprehensive Model, suggesting that this phenomenon persists over several years and even decades. The reason for this lead is unclear. For some UT, the lead seems to be caused, or at least enhanced, by the presence of a nearby ocean to the West of the primary current system, facilitating the circulation of induced currents in that area (see, e.g., UT $=12$ and $\mathrm{UT}=18$, in both hemispheres). However, the induced field also leads the primary field over continents (see, e.g., UT $=6$, Northern hemisphere). We also notice relatively larger induced fields at night, which is expected since the mantle and subsurface stay conducting at night, unlike the E-region of the ionosphere. Similar results were found for the other seasons (not shown).

\section{Conclusion and outlook}

In the present paper, we reported on a new quiet-time, Sq and EEJ spherical harmonic field model, DIFI-2015b, derived from a combination of Swarm satellite and ground observatory data between December 2013 and July 2015. This model was calculated using a so-called Dedicated Inversion algorithm developed as part of the Swarm level 2 data processor and where the average quiet-time ionospheric field is modeled after removing contributions from all other sources to the measured magnetic field. The algorithm separates the primary and induced fields using a $3 \mathrm{D}$ conductivity model with a surface shell on top of a 1D mantle conductivity profile. The parameterization includes Fourier series for diurnal and seasonal variations and a linear dependence with respect to the solar radio flux index. 


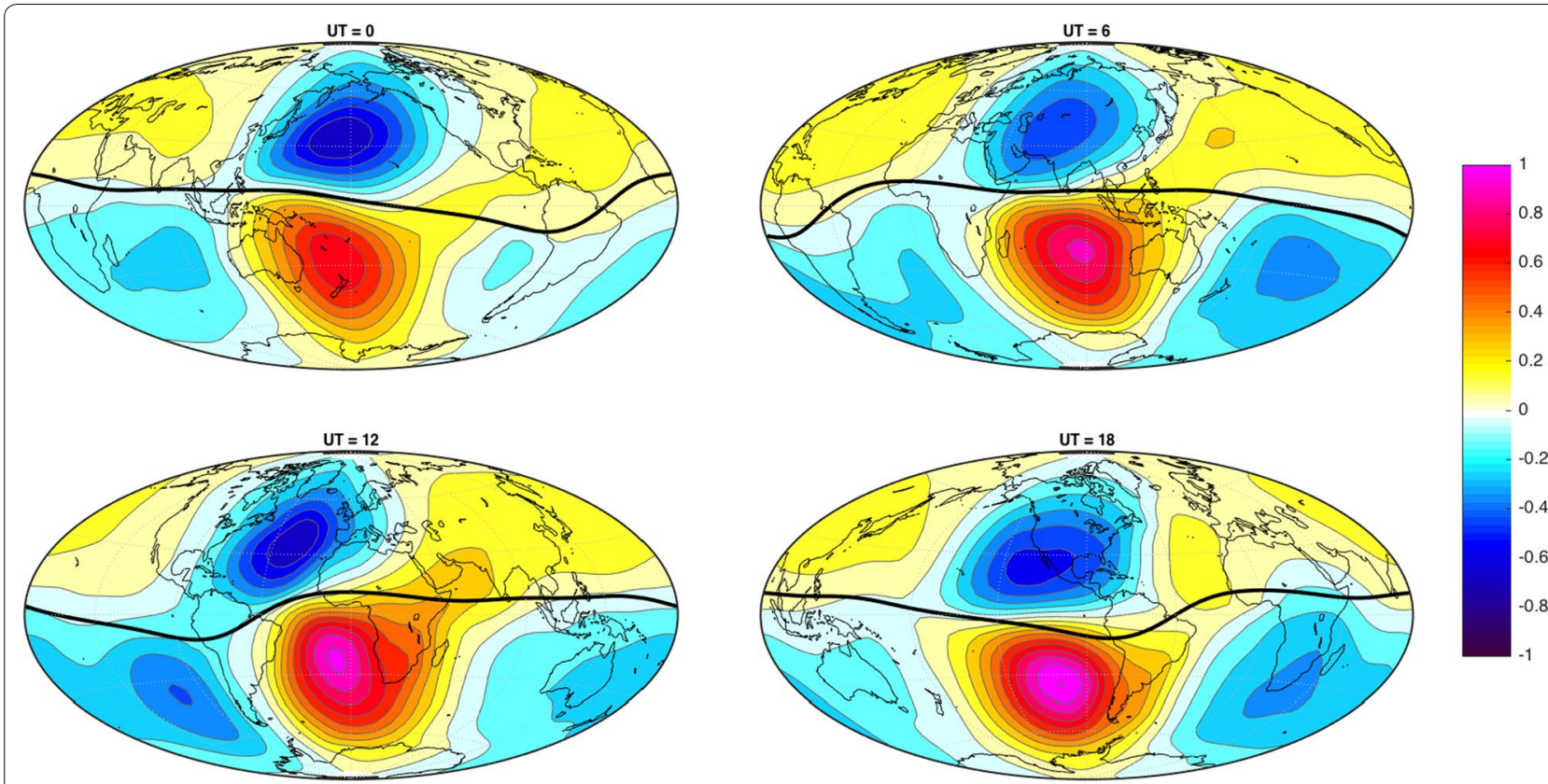

Fig. 14 (Normalized) induced equivalent current function $\Psi_{2}$ (currents formally assumed to flow at Earth's surface), DIFI-2015b model, for April 1, $\mathrm{UT}=12$ and $F_{10.7}=100 \mathrm{SFU} . \Psi_{2}$ is normalized by the maximum value for all seasons. A $8.2 \mathrm{kA}$ current flows between the contours. The dip equator is depicted as a black line

DIFI-2015b satisfactorily fits both the satellite and observatory data, with very little bias and RMS misfits around $7 \mathrm{nT}$ on the ground and up to $10 \mathrm{nT}$ at satellite altitude. The data residuals reflect the day-to-day variability of the Sq and EEJ currents, as well as the contamination by IHFAC fields on the polar and azimuthal components at satellite altitude. The data fit deteriorates somewhat at one ground location away from the observatories used in the inversion dataset. However, the current performance assessment will have to be re-examined in the future, based on more independent data. This could be done either by waiting until more observatory data become available for the considered time interval, or by calculating new models from subsampled datasets. Satellite data could also be subsampled to determine the robustness of the model, but a larger time interval will be needed first to ensure full local time coverage for all subsamples.

Another way to validate results from the DIFI algorithm will be to compare it with other relevant ionospheric data products derived from Swarm. One type of such products is the model output of the Comprehensive Inversion (CI) algorithm (Sabaka et al. 2013), an updated, Swarm-based version of the CM. Preliminary comparisons revealed generally good agreement between the latest version of the CI model and DIFI-2015b, but more detailed comparisons will be needed in the future. EEJ estimates derived as part of the calculation of the
Swarm-based equatorial electric field (EEF) estimates (Alken et al. 2015b) could also provide useful constraints on DIFI models in the equatorial region.

The DIFI-2015b model confirmed previously known features of the Sq field such as the LT advance of the summer current system with respect to the winter current system, the current systems seasonal asymmetry with respect to solstices, the effect of the magnetic dip equator on the current system morphology and westward drift speed and the small lead of the induced current system with respect to the primary current system. It also revealed some new, interesting features that are specific to the Southern hemisphere and went unnoticed until now (to our knowledge): (a) a peculiar seasonal variation where the largest total Sq currents are found in the spring rather than in the winter (i.e., southern summer) and (b) a wave-4 structure in the longitudinal variation of the total Sq currents. Both phenomena are enhanced in the American sector, where the dip equator is bended, which suggests some coupling between the EEJ and Sq, in agreement with some earlier studies.

The DIFI-2015b is available from https://geomag.colorado.edu/geomagnetic-and-electric-field-models.html. An earlier version, DIFI-2015a, was built from a satellite dataset covering a smaller time interval and using a less recent mantle conductivity model; this version is available as version 0101 from the Swarm data access Web site at https://earth.esa.int/web/guest/swarm/data-access. 


\section{Authors' contributions}

AC designed the DIFI algorithm, wrote the associated software and drafted the manuscript. PV helped to design and write the software, implemented it in the Swarm level 2 environment and ran it for multiple parameters and datasets. GH helped to analyze and interpret the results and to draft the manuscript. All authors read and approved the final manuscript.

\section{Author details}

${ }^{1}$ Cooperative Institute for Research in Environmental Sciences, University of Colorado Boulder and NOAA National Centers for Environmental Information, 325 Broadway, Boulder, CO 80305-3328, USA. ${ }^{2}$ Institut de Physique du Globe de Paris, Sorbonne Paris Cité, Université Paris Diderot, CNRS, 1 rue Jussieu, 75005 Paris, France.

\section{Acknowledgements}

The DIFI algorithm development was funded by the European Space Agency through ESTEC contracts 4000102140/10/NL/JA "Development of the Swarm Level 2 Algorithms and Associated Level 2 Processing Facility" and 4000109587/13/I-NB "SWARM ESL", as well as by the Centre National d'Etudes Spatiales through the "Travaux préparatoires et exploitation de la mission Swarm" project. We thank Patrick Alken for providing us with an updated version of his core field model, Alexei Kuvshinov for making available to us his updated $\mathbf{Q}$ matrix and Nils Olsen for helpful discussions at various stages of this work. This is IPGP contribution \#3735.

\section{Competing interests}

The authors declare that they have no competing interests.

\section{Received: 24 February 2016 Accepted: 30 May 2016}

Published online: 13 June 2016

\section{References}

Alken P, Maus S, Chulliat A, Manoj C (2015a) NOAA/NGDC candidate models for the 12th generation International Geomagnetic Reference Field. Earth Planets Space 67:68. doi:10.1186/s40623-015-0215-1

Alken P, Maus S, Chulliat A, Vigneron P, Sirol O, Hulot G (2015b) Swarm equatorial electric field chain: first results. Geophys Res Lett 42:673-680. doi:10.1 002/2014GL062658

Baumjohann W, Nakamura R (2009) Magnetospheric contributions to the terrestrial magnetic field. In: Kono M, Schubert G (eds) Treatise on geophysics-geomagnetism. Elsevier, Amsterdam, pp 77-92

Bhardwaj SK, Subba Rao PBV, Veenadhari B (2015) Abnormal quiet day variations in Indian region along $75^{\circ}$ E meridian. Earth Planets Space 67:115. doi:10.1186/s40623-015-0292-1

Campbell WH (1989) The regular geomagnetic field variations during quiet solar conditions. In: Jacobs JA (ed) Geomagnetism, vol 3. Academic, San Diego, pp 385-460

Chapman S, Bartels J (1940) Geomagnetism. Oxford University Press, London

Chen G-X, Xu W-Y, Du A-M, Wu Y-Y, Chen B, Liu X-C (2007) Statistical characteristics of the day-to-day variability in the geomagnetic Sq field. J Geophys Res 112:A06320. doi:10.1029/2006JA012059

Chulliat A, Blanter E, Le Mouël J-L, Shnirman M (2005) On the seasonal asymmetry of the diurnal and semidiurnal geomagnetic variations. J Geophys Res 110:A05301. doi:10.1029/2004JA010551

Chulliat A, Vigneron P, Thébault E, Sirol O, Hulot G (2013) Swarm SCARF dedicated ionospheric field inversion chain. Earth Planets Space 65:12711283. doi:10.5047/eps.2013.08.006

Forbes JM (1981) The equatorial electrojet. Rev Geophys Space Phys 19(3):469-504

Fratter I, Léger JM, Bertrand F, Jager T, Hulot G, Brocco L, Vigneron P (2016) Swarm absolute scalar magnetometers first in-orbit results. Acta Astronaut 121:76-87. doi:10.1016/j.actaastro.2015.12.025

Friis-Christensen E, Lühr H, Hulot G (2006) Swarm: a constellation to study the Earths magnetic field. Earth Planets Space 58:351-358

Hamilton B (2013) Rapid modelling of the large-scale magnetospheric field from Swarm satellite data. Earth Planets Space 65:1295-1308

Hulot G, Vigneron P, Léger JM, Fratter I, Olsen N, Jager T, Bertrand F, Brocco L, Sirol O, Lalanne X, Boness A, Cattin V (2015) Swarm's absolute magnetometer experimental vector mode, an innovative capability for space magnetometry. Geophys Res Lett. doi:10.1002/2014GL062700

Kuvshinov A, Olsen N (2006) A global model of mantle conductivity derived from 5 years of CHAMP, Ørsted, and SAC-C magnetic data. Geophys Res Lett 33:L18301. doi:10.1029/2006GL027083

Léger JM, Jager T, Bertrand F, Hulot G, Brocco L, Vigneron P, Lalanne X, Chulliat A, Fratter I (2015) In-flight performance of the Absolute Scalar Magnetometer vector mode on board the Swarm satellites. Earth Planets Space 67:57. doi:10.1186/s40623-015-0231-1

Lühr H, Maus S (2010) Solar cycle dependence of quiet-time magnetospheric currents and a model of their near-Earth magnetic fields. Earth Planets Space 62:843-848

Lühr H, Rother M, Häusler K, Fejer B, Alken P (2012) Direct comparison of nonmigrating tidal signatures in the electrojet, vertical plasma drift and equatorial ionization anomaly. J Atmos Solar Terr Phys 75-76:31-43. doi:10.1016/j.jastp.2011.07.009

Lühr H, Kervalishvili G, Michaelis I, Rauberg J, Ritter P, Park J, Merayo JMG, Brauer $P$ (2015) The interhemispheric and $F$ region dynamo currents revisited with the Swarm constellation. Geophys Res Lett. doi:10.1002/2 015GL063662

Macmillan S, Olsen N (2013) Observatory data and the Swarm mission. Earth Planets Space 65:1355-1362

Manoj C, Kuvshinov A, Maus S, Lühr H (2006a) Ocean circulation generated magnetic signals. Earth Planets Space 58:429-437

Manoj C, Lühr H, Maus S, Nagarajan N (2006b) Evidence for short spatial correlation lengths of the noontime equatorial electrojet inferred from a comparison of satellite and ground magnetic data. J Geophys Res 111:A11312. doi:10.1029/2006JA011855

Matsushita S, Maeda H (1965) On the geomagnetic solar quiet daily variation field during the IGY. J Geophys Res 70(11):2535-2558

Maus S, Lühr H (2005) Signature of the quiet-time magnetospheric magnetic field and its electromagnetic induction in the rotating Earth. Geophys J Int 162:755-763. doi:10.1111/j.1365-246X.2005.02691.x

Maus S, Yin F, Lühr H, Manoj C, Rother M, Rauberg J, Michaelis I, Stolle C, Mller RD (2008) Resolution of direction of oceanic magnetic lineations by the sixth-generation lithospheric magnetic field model from CHAMP satellite magnetic measurements. Geochem Geophys Geosyst. doi:10.1029/200 $8 \mathrm{GC001949}$

Olsen N (1993) The solar cycle variability of lunar and solar daily geomagnetic variations. Ann Geophys 11:254-262

Olsen N, Friis-Christensen E, Floberghagen R, Alken P, Beggan CD, Chulliat A, Doornbos E, da Encarnação JT, Hamilton B, Hulot G, van den IJssel J, Kuvshinov A, Lesur V, Lühr H, Macmillan S, Maus S, Noja M, Olsen PEH, Park J, Plank G, Püthe C, Rauberg J, Ritter P, Rother M, Sabaka TJ, Schachtschneider R, Sirol O, Stolle C, Thébault E, Thomson AWP, Tøffner-Clausen L, Velímský J, Vigneron P, Visser PN (2013) The swarm satellite constellation application and research facility (SCARF) and swarm data products. Earth Planets Space 65:1189-1200

Olsen N, Hulot G, Lesur V, Finlay CC, Beggan C, Chulliat A, Sabaka TJ, Floberghagen R, Friis-Christensen E, Haagmans R, Kotsiaros S, Lühr H, TøffnerClausen L, Vigneron P (2015) The swarm initial field model for the 2014 geomagnetic field. Geophys Res Lett. doi:10.1002/2014GL062659

Peltier A, Chulliat A (2010) On the feasibility of promptly producing quasi-definitive magnetic observatory data. Earth Planets Space 62(2):e5-e8

Püthe C, Kuvshinov A, Khan A, Olsen N (2015) A new model of Earth's radial conductivity structure derived from over 10 years of satellite and observatory magnetic data. Geophys J Int 203(3):1864-1872. doi:10.1093/gji/ggv407

Rastogi RG, lyer KN (1976) Quiet day variation of geomagnetic H-field at low latitudes. J Geomag Geoelectr 28:461-479

Richmond AD (1995) lonospheric electrodynamics using magnetic apex coordinates. J Geomag Geoelectr 47:191-212. doi:10.5636/jgg.47.191

Richmond AD, Thayer JP (2000) lonospheric electrodynamics: a tutorial. In: Magnetospheric current systems. Geophysical Monograph 118, American Geophysical Union, pp 131-146

Rother M, Lesur V, Schachtschneider R (2013) An algorithm for deriving core magnetic field models from the Swarm data set. Earth Planets Space 65:1223-1231

Sabaka TJ, Olsen N, Langel RA (2002) A comprehensive model of the quiettime, near-Earth magnetic field: phase 3. Geophys J Int 151:32-68. doi:10.1046/j.1365-246X.2002.01774.X 
Sabaka TJ, Olsen N, Purucker ME (2004) Extending comprehensive models of the Earth's magnetic field with Ørsted and CHAMP data. Geophys J Int 159:521-547. doi:10.1111/j.1365-246X.2004.02421.X

Sabaka TJ, Tøffner-Clausen L, Olsen N (2013) Use of the comprehensive inversion method for Swarm satellite data analysis. Earth Planets Space 65:1201-1222

Sabaka TJ, Olsen N, Tyler RH, Kuvshinov A (2015) CM5, a pre-Swarm comprehensive geomagnetic field model derived from over $12 \mathrm{yr}$ of CHAMP, Ørsted, SAC-C and observatory data. Geophys J Int 200:1596-1626

Stening RJ (1995) Variations in the strength of the Sq current system. Ann Geophys 13:627-632

Takeda M (2002) Features of global geomagnetic Sq field from 1980 to 1990. J Geophys Res 107(A9):1252. doi:10.1029/2001JA009210

Thébault E, Vigneron P, Maus S, Chulliat A, Sirol O, Hulot G (2013) Swarm SCARF dedicated lithospheric field inversion chain. Earth Planets Space 65:1257-1270
Vigneron P, Hulot G, Olsen N, Léger JM, Jager T, Brocco L, Sirol O, Coïsson P, Lalanne X, Chulliat A, Bertrand F, Boness A, Fratter I (2015) A 2015 international geomagnetic reference field (IGRF) candidate model based on Swarm's experimental absolute magnetometer vector mode data. Earth Planets Space 67:95. doi:10.1186/s40623-015-0265-4

Yamazaki Y, Yumoto K, Cardinal MG, Fraser BJ, Hattori P, Kakinami Y, Liu JY, Lynn KJW, Marshall R, McNamara D, Nagatsuma T, Nikiforov VM, Otadoy RE, Ruhimat M, Shevtsov BM, Shiokawa K, Abe S, Uozumi T, Yoshikawa A (2011) An empirical model of the quiet daily geomagnetic field variation. J Geophys Res 116:A10312. doi:10.1029/2011JA016487

Yamazaki Y, Richmond AD, Maute A, Liu H-L, Pedatella N, Sassi F (2014) On the day-to-day variation of the equatorial electrojet during quiet periods. J Geophys Res Space Phys. doi:10.1002/2014JA020243

\section{Submit your manuscript to a SpringerOpen ${ }^{\circ}$ journal and benefit from:}

- Convenient online submission

- Rigorous peer review

- Immediate publication on acceptance

- Open access: articles freely available online

- High visibility within the field

- Retaining the copyright to your article 